NBER WORKING PAPER SERIES

\title{
ARE COLLATERAL-CONSTRAINT MODELS READY FOR MACROPRUDENTIAL POLICY DESIGN?
}

\author{
Pablo Ottonello \\ Diego J. Perez \\ Paolo Varraso \\ Working Paper 29204 \\ http://www.nber.org/papers/w29204 \\ NATIONAL BUREAU OF ECONOMIC RESEARCH \\ 1050 Massachusetts Avenue \\ Cambridge, MA 02138 \\ September 2021
}

We thank our discussants, Louphou Coulibaly, Sebastian Fanelli, and Facundo Piguillem, as well as Javier Bianchi, Roberto Chang, Enrique Mendoza, and Martin Uribe for helpful comments and suggestions. The views expressed herein are those of the authors and do not necessarily reflect the views of the National Bureau of Economic Research.

NBER working papers are circulated for discussion and comment purposes. They have not been peer-reviewed or been subject to the review by the NBER Board of Directors that accompanies official NBER publications.

(C) 2021 by Pablo Ottonello, Diego J. Perez, and Paolo Varraso. All rights reserved. Short sections of text, not to exceed two paragraphs, may be quoted without explicit permission provided that full credit, including $\left({ }^{\circ}\right.$ notice, is given to the source. 
Are Collateral-Constraint Models Ready for Macroprudential Policy Design?

Pablo Ottonello, Diego J. Perez, and Paolo Varraso

NBER Working Paper No. 29204

September 2021

JEL No. E32,E44,F32,F36,F38,G01

\section{ABSTRACT}

We study the design of macroprudential policies based on quantitative collateral-constraint models. We show that the desirability of macroprudential policies critically depends on the specific form of collateral used in debt contracts: While inefficiencies arise when current prices affect collateral---a frequent benchmark used to guide policies---they do not when only future prices affect collateral. Since the microfoundations and quantitative predictions of models with future-price collateral constraints do not appear less plausible than those using current prices, we conclude that additional empirical work is essential for the use of these models in macroprudential policy design.

Pablo Ottonello

Department of Economics

University of Michigan

611 Tappan Street

Ann Arbor, MI 48109

and NBER

pottonel@umich.edu

Diego J. Perez

Department of Economics

New York University

19 West 4th Street

New York, NY 10012

and NBER

diego.perez@nyu.edu
Paolo Varraso

pv773@nyu.edu 


\section{Introduction}

The last decade experienced a paradigm shift with respect to capital-control policies. Central policy institutions, such as the International Monetary Fund and the World Bank, shifted toward an open approach to the implementation of capital controls, especially when these are aimed at preventing excessive borrowing and financial instability, also known as "macroprudential policies." ${ }^{1}$ Currently, capital-control policies are part of the standard toolkit used by emerging-market policymakers worldwide (see, for example, Fernández et al., 2016). This is in sharp contrast to the conventional post-Bretton Woods opinion prior to the global financial crisis, which viewed these policies as impediments to the flow of capital to where it was most needed.

At the core of this change in paradigm was the large body of academic research linked to financial-friction-driven inefficient borrowing. The first building block of this literature was theoretical. Important contributions include Geanakoplos and Polemarchakis (1986); Kehoe and Levine (2001); and Lorenzoni (2008). ${ }^{2}$ The second building block was the set of quantitative models with collateral constraints, which show that by implementing state-contingent capital-control taxes, economies can significantly reduce the probability of financial crises and improve welfare (Bianchi (2011); Benigno et al. (2013); Bianchi and Mendoza (2018)).

In this paper, we ask to what extent is the current generation of quantitative collateralconstraint models ready to be used in the design of macroprudential policies. Starting from a incomplete-markets model with a general specification of collateral constraints, we show that the desirability of macroprudential policies critically depends on the specific form of collateral used in debt contracts: Whereas inefficiencies arise when current prices affect collateral, they do not when only future prices affect collateral. We show that the microfoundations and quantitative predictions of collateral-constraint models linked to future prices do not appear less plausible than those using current prices. This leads us to conclude that a third building

\footnotetext{
${ }^{1}$ See Arora et al. (2013) for a recent discussion of the IMF's view on capital controls and macroprudential policies.

${ }^{2}$ Other literature associates borrowing inefficiencies with nominal rigidities. See, for example, Farhi and Werning (2016) and Schmitt-Grohé and Uribe (2016). These models are outside the focus of this paper.
} 
block in this literature is necessary for the use of capital-control models for macroprudential policy design: direct empirical evidence on the policy transmission featured in these models, which helps determine the extent to which capital controls affect collateral values and, therefore, possible inefficiencies.

The paper begins by laying out a canonical small open economy with tradable and nontradable goods and external borrowing subject to collateral constraints. We consider a general formulation of borrowing constraints (Farhi and Werning, 2016) that nests forms used frequently in the literature. One of these is borrowing linked to current income. As shown in Bianchi (2011), these economies generally feature inefficient borrowing. Another important form is borrowing linked to future income (similar to Kiyotaki and Moore, 1997, but with income instead of capital as collateral). In this case, we show that a policymaker with access to capital-control taxes that lacks commitment cannot improve welfare relative to the competitive-equilibrium allocation. Moreover, we show that any borrowing constraint that features only future prices as collateral is constrained efficient. We show that this result also holds in a model in which capital is used as collateral.

We then discuss the challenges of distinguishing between borrowing constraints with current or future income as collateral. We begin by discussing their theoretical microfoundations. On the one hand, collateral constraints that use future income emerge from a standard environment in which borrowers lack commitment to repay their debts akin to that studied by Eaton and Gersovitz (1981); lenders can seize a fraction of their income if borrowers default, and are only willing to offer risk-free debt contracts. On the other hand, collateral constraints that use current income requires the assumption that borrowers can run away in the period in which they borrow (but not in the repayment period); lenders can seize a fraction of their income in that state, and are only willing to offer risk-free debt contracts. From the perspective of microfoundations, it is therefore hard to rule out that future income is the main source of collateral in debt contracts.

We then study the quantitative properties of both models - current and future income as collateral - and show that both predict similar aggregate dynamics. In particular, both models deliver business-cycle predictions aligned with the patterns observed in emerging mar- 
ket economies, including excess volatility of consumption over income, countercyclical trade balance, and episodes of sudden stops. In the model with current-income collateral, these properties emerge due to the Fisherian debt-deflation amplification mechanism, by which tightenings in collateral constraints lead to consumption contractions, price adjustments, and further tightening of the collateral constraint (see Korinek and Mendoza, 2014, for a survey of models that feature this mechanism). In the model with future-income collateral, these properties arise from shocks to the pledgeability of collateral, which is a frequent source of shock in macro-finance models (see, for example, Khan and Thomas, 2013; Guerrieri and Lorenzoni, 2017; Bianchi and Mendoza, 2018). The similarity of these models' predictions implies that it is hard to distinguish them without direct empirical evidence of the borrowing constraint's specific form.

We then ask whether the distinction between these classes of models matters for welfare. For this, we study the welfare costs of model misspecification in policy design. First, we show that not implementing macroprudential policies in an inefficient economy with currentincome collateral entails large welfare costs. Second, we analyze the welfare consequences of designing macroprudential policies that assume that the economy has current-income borrowing constraints, but in fact it has future-price borrowing constraints. We show that capital controls still reduce external borrowing and the incidence of crises, but they also reduce households' welfare by around $0.01 \%$ on average. These welfare losses are smaller than those of not implementing policies in an inefficient economy. Yet the welfare results show that there are large potential gains from identifying the form of financial frictions in more detail.

Finally, we stress that the absence of macroprudential policies in models with future income as collateral extends to an environment in which the government can commit to its future policies. In this case, although the competitive equilibrium is no longer efficient, the government does not find it optimal to tax household borrowing prior to a crisis. Instead, the optimal policy features a forward-guidance component once the crisis hits, which involve promised debt subsidies during the recovery. 
Layout The rest of the paper is organized as follows. Section 2 presents the general framework. Section 3 discusses the efficiency of different specific collateral-constraint forms in this framework. Section 4 discusses microfoundations and quantitative predictions of alternative models, as well as quantifies the welfare costs of model misspecification in policy design. Section 5 studies the extensions with commitment and capital used as collateral, and Section 6 concludes.

\section{Theoretical Framework}

We consider a canonical, dynamic, small open economy with risk-averse households that consume tradable and nontradable goods, receive a stochastic income, and borrow from the rest of the world in non-state-contingent debt securities subject to collateral constraints. The model nests alternative forms of collateral constraints considered in the literature.

Time is discrete and infinite. Each period $t \geq 0$, a stochastic event, $s_{t} \in S$, is realized, where $S$ is a compact set. We assume $s_{t}$ follows a Markov process with transition probability function $\Gamma_{s}\left(s_{t+1}, s_{t}\right)$. Let $s^{t}=\left[s_{0}, s_{1}, . ., s_{t}\right]$ denote the history of events until time $t$. The domestic economy is populated by a representative household with preferences over consumption described by the lifetime utility function

$$
\mathbb{E}_{0} \sum_{t=0}^{\infty} \beta^{t} u\left(c_{t}\left(s^{t}\right)\right),
$$

where $c_{t}\left(s^{t}\right)$ denotes consumption in period $t$ and state history $s^{t} ; u: \mathbb{R}_{+} \rightarrow \mathbb{R}$ is a differentiable, increasing, and concave function; $\beta \in(0,1)$ denotes the subjective discount factor; and $\mathbb{E}_{t}$ denotes the expectation conditional on the information set available in state $s^{t}$. The consumption good is a composite of tradable and nontradable goods, $c_{t}\left(s^{t}\right)=A\left(c_{t}^{\mathrm{T}}\left(s^{t}\right), c_{t}^{\mathrm{N}}\left(s^{t}\right)\right)$, where $c_{t}^{\mathrm{T}}\left(s^{t}\right)$ and $c_{t}^{\mathrm{N}}\left(s^{t}\right)$ denote tradable and nontradable consumption, and $A: \mathbb{R}_{+}^{2} \rightarrow \mathbb{R}_{+}$is a differentiable function, increasing in both arguments, concave, and homogeneous of degree one.

Households are endowed each period with a stochastic endowment of tradable and 
nontradable goods, $y_{t}^{\mathrm{T}}\left(s^{t}\right)$ and $y_{t}^{\mathrm{N}}\left(s^{t}\right)$. Households have access to one-period, non-statecontingent bonds denominated in foreign currency that can be traded internationally and pay a borrowing rate $R$, which is taken as given by agents in the small open economy. Households' sequential budget constraint, expressed in units of tradables, is then given by

$$
c_{t}^{\mathrm{T}}\left(s^{t}\right)+p_{t}\left(s^{t}\right) c_{t}^{\mathrm{N}}\left(s^{t}\right)+R d_{t}\left(s^{t-1}\right)=d_{t+1}\left(s^{t}\right)+y_{t}^{\mathrm{T}}\left(s^{t}\right)+p_{t}\left(s^{t}\right) y_{t}^{\mathrm{N}}\left(s^{t}\right)
$$

where $d_{t+1}\left(s^{t}\right)$ denotes the level of debt issued in period $t$ and due in period $t+1$ and $p_{t}\left(s^{t}\right)$ denotes the relative price between nontradable and tradable goods.

When borrowing, households face a collateral constraint:

$$
d_{t+1}\left(s^{t}\right) \leq \bar{d}\left(\left\{p_{t+h}\left(s^{t+h}\right), s^{t+h}\right\}_{h=0, s^{t+h} \in S^{t+h}}^{H}\right),
$$

for $H$ arbitrarily large; where $S^{t+h}=\left\{s^{t}, s_{t+1}, s_{t+2}, . ., s_{t+h}\right\}_{s_{t+j} \in S, j \in[0,1, \ldots h]}$ denotes the set of all possible histories that contain $s^{t}$ and $\left\{p_{t+h}\left(s^{t+h}\right), s^{t+h}\right\}_{h=0, s^{t+h} \in S^{t+h}}^{\infty}$ denotes the vector of prices and exogenous states. This general form of borrowing constraint follows Farhi and Werning (2016) and encompasses some forms of borrowing constraints frequently used in the literature. For instance, it nests two special cases of particular interest:

i. Current income as collateral

$$
\bar{d}\left(\left\{p_{t+h}\left(s^{t+h}\right), s^{t+h}\right\}_{h=0, s^{t+h} \in S^{t+h}}^{\infty}\right)=\kappa\left(s^{t}\right)\left(y_{t}^{\mathrm{T}}\left(s^{t}\right)+p_{t}\left(s^{t}\right) y_{t}^{\mathrm{N}}\left(s^{t}\right)\right)
$$

This is a form of collateral constraint frequently used in the literature, introduced by Mendoza (2002) to study the role of currency mismatch in emerging-market fluctuations and in Bianchi (2011) to study capital-control policies. We refer to this as the currentincome constraint. 
ii. Next-period income as collateral

$$
\bar{d}\left(\left\{p_{t+h}\left(s^{t+h}\right), s^{t+h}\right\}_{h=0, s^{t+h} \in S^{t+h}}^{\infty}\right)=\min _{\substack{\left.\left\{y_{t+1}^{\mathrm{T}}\left(s^{t+1}\right), y_{t+1}^{\mathrm{N}}\left(s^{t+1}\right), p_{t+1}\left(s^{t+1}\right)\right\} \mid s^{t}\right\}}} \kappa\left(s^{t}\right)\left(y_{t+1}^{\mathrm{T}}\left(s^{t+1}\right)+p_{t+1}\left(s^{t+1}\right) y_{t}^{\mathrm{N}}\left(s^{t+1}\right)\right)
$$

This case corresponds to a similar constraint considered by Kiyotaki and Moore (1997), in which income instead of capital is used as collateral. We refer to this as the futureincome constraint.

As we further discuss in Section 4.1, this type of constraint can be microfounded in an environment in which households lack commitment to repay debt and lenders are only willing to offer default-free debt contracts. In this environment the minimum operator ensures debt repayment in every state. Our results also hold for other ways of summarizing the stochastic the value of future income, including expected values as in the work of Devereux et al. (2019).

In both cases we allow the parameter $\kappa\left(s^{t}\right)$ to be stochastic, as in several papers considered in this literature.

We set up the household problem recursively. The aggregate state in the economy is $\mathbf{s}=(d, D, s)$, where $d$ is the idiosyncratic household's level of debt, $D$ is the aggregate level of debt, and $s$ is the exogenous state. The household's problem is given by

$$
\begin{array}{cl} 
& V(\mathbf{s})=\max _{c^{\mathrm{T}}, c^{\mathrm{N}}, d^{\prime}} u\left(A\left(c^{\mathrm{T}}, c^{\mathrm{N}}\right)\right)+\beta \mathbb{E}\left[V\left(\mathbf{s}^{\prime}\right)\right] \\
\text { subject to } \quad & c^{\mathrm{T}}+p(D, s) c^{\mathrm{N}}+R d=d^{\prime}+y^{\mathrm{T}}+p(D, s) y^{\mathrm{N}}, \\
& d^{\prime} \leq \bar{d}\left(\left\{p\left(D^{(h)}, s^{(h)}\right), s^{(h)}\right\}_{h=0}^{H}\right), \\
& D^{(h)}=\mathcal{D}\left(D^{(h-1)}, s^{(h-1)}\right), \quad \Gamma^{(h)}\left(s^{(h)}, s\right), \quad \text { for } 1 \leq h \leq H,
\end{array}
$$

where $p(D, s)$ is the relative price function; $\mathcal{D}(D, s)$ is the conjecture of aggregate debt; $D^{(h)}, s^{(h)}$ refer to the aggregate debt and exogenous state $h$ periods ahead; and $\Gamma^{(h)}\left(s^{(h)}, s\right)=$ $\prod_{j=1}^{h} \Gamma\left(s^{(j)}, s^{(j-1)}\right)$ is a transition probability function from state $s$ to state $s^{(h)}$. 
Denoting by $\mu \geq 0$ the Lagrange multiplier associated with collateral constraint (2), the first-order conditions of the household's problem are

$$
\begin{aligned}
u_{\mathrm{T}}\left(c^{\mathrm{T}}, c^{\mathrm{N}}\right) & =\beta R \mathbb{E}_{t} u_{T}\left(c^{\mathrm{T}^{\prime}}, c^{\mathrm{N}^{\prime}}\right)+\mu \\
\frac{A_{N}\left(c^{\mathrm{T}}, c^{\mathrm{N}}\right)}{A_{T}\left(c^{\mathrm{T}}, c^{\mathrm{N}}\right)} & =p(D, s)
\end{aligned}
$$

and the complementary slackness condition is

$$
\mu\left(\bar{d}\left(\left\{p\left(D^{(h)}, s^{(h)}\right), s^{(h)}\right\}_{h=0}^{H}\right)-d^{\prime}\right)=0
$$

where $u_{X}\left(c^{\mathrm{T}}, c^{\mathrm{N}}\right) \equiv \frac{\partial u\left(A\left(c^{\mathrm{T}}, c^{\mathrm{N}}\right)\right)}{\partial c_{t}^{X}}$ and $A_{X}\left(c^{\mathrm{T}}, c^{\mathrm{N}}\right) \equiv \frac{\partial A\left(c^{\mathrm{T}}, c^{\mathrm{N}}\right)}{\partial c^{X}}$ for $X=\{\mathrm{T}, \mathrm{N}\}$

Equilibrium. A recursive competitive equilibrium is defined as follows.

Definition 1. A recursive competitive equilibrium is a set of policy functions $\mathbf{x}(\mathbf{s}) \equiv$ $\left\{c^{\mathrm{T}}(\mathbf{s}), c^{\mathrm{N}}(\mathbf{s}), d^{\prime}(\mathbf{s})\right\}$, a price function $p(D, s)$, and a conjecture policy $\mathcal{D}(D, s)$ such that

1. Policy functions solve household's problem $(\mathrm{P})$.

2. The market for nontradable goods clears, $c^{\mathrm{N}}=y^{\mathrm{N}}$.

3. Conjectures are consistent with the policy functions, $\mathcal{D}(D, s)=d^{\prime}(D, s)$.

\section{Efficiency}

Using the framework of Section 2, we now study the efficiency of different types of specific collateral constraints. The next sections discuss the microfoundations and quantitative properties of each of these specific models.

We formulate the optimal policy for a benevolent government that can tax households' borrowing and lacks commitment regarding its policies. We focus on the notion of Markov Perfect Equilibrium in which the actions of the current planner depend on payoff-relevant 
states, taking as given the actions of future planners. ${ }^{3}$ Thus, the current planner chooses consumption and borrowing to solve the following problem:

$$
W(D, s)=\max _{c^{\mathrm{T}}, c^{\mathrm{N}}, D^{\prime}} u\left(A\left(c^{\mathrm{T}}, c^{\mathrm{N}}\right)\right)+\beta \mathbb{E}\left[W\left(D^{\prime}, s^{\prime}\right)\right]
$$

subject to $\quad c^{\mathrm{T}}=y^{\mathrm{T}}+D^{\prime}-R D, \quad c^{\mathrm{N}}=y^{\mathrm{N}}$

$$
\begin{aligned}
& D^{\prime} \leq \bar{d}\left(\left\{p^{(h)}\left(D^{(h)}, s^{(h)}\right), s^{(h)}\right\}_{h=0}^{H}\right), \\
& p^{(0)}(D, s)=\frac{A_{N}\left(c^{\mathrm{T}}, c^{\mathrm{N}}\right)}{A_{T}\left(c^{\mathrm{T}}, c^{\mathrm{N}}\right)}, \\
& p^{(h)}\left(D^{(h)}, s^{(h)}\right)=\mathcal{P}\left(D^{(h)}, s^{(h)}\right), D^{(h+1)}=\mathcal{D}\left(D^{(h)}, s^{(h)}\right), \Gamma^{(h)}\left(s^{(h)}, s\right), \text { for } 1 \leq h \leq H,
\end{aligned}
$$

where $\mathcal{D}\left(D^{(h)}, s^{(h)}\right)$ and $\mathcal{P}\left(D^{(h)}, s^{(h)}\right)$ are the planner's conjectures for future debt and prices.

The first restriction is the resource constraint, obtained by imposing market clearing of non-tradable goods. The second restriction is the borrowing constraint and the third is the implementability condition on the relative price of nontradables. The last constraints state that the current planner takes as given the price and debt policies of future planners. Notice that the planner takes into account the effect of its choice of debt on current prices and on the consumption decisions of future planners that, in turn, feed into the debt limit through future prices.

A constrained-efficient equilibrium is a fixed point between the planner's current and future policies. This notion of constrained efficiency is formalized as follows:

Definition 2. A constrained-efficient allocation is a set of policy functions $\mathbf{x}^{S P}(D, s) \equiv$ $\left\{c^{\mathrm{T}}(D, s), c^{\mathrm{N}}(D, s), D^{\prime}(D, s)\right\}$ and conjectured policies $\mathcal{D}(D, s)$ and $\mathcal{P}(D, s)$ such that

\section{Policy functions solve the planner's problem (SP).}

2. Conjectures are consistent with policy functions $\mathcal{D}(D, s)=D^{\prime}(D, s)$ and $p_{0}(D, s)=$ $\mathcal{P}(D, s)$.

\footnotetext{
${ }^{3}$ This formulation rules out reputational-type equilibria; for an analysis of these types of equilibria in policy games with time inconsistency, see Chari and Kehoe (1990) and Chang (1998). This formulation does not guarantee uniqueness of equilibrium. For an analysis of multiplicity of equilibria in a model in which current prices affect collateral, see Schmitt-Grohé and Uribe (2021).
} 
Equipped with this definition, the following theorem establishes conditions under which the decentralized equilibrium is constrained efficient.

Theorem 1. Consider a solution of the planner's problem in which the consumption function $c(D, s)$ is differentiable and non-increasing in debt D. If $\bar{d}\left(\left\{p^{(h)}, s^{(h)}\right\}_{h=0}^{H}\right)$ is differentiable and non-decreasing in $p^{(h)}$ for all $s^{(h)}$ and $\frac{\partial \bar{d}\left(\left\{p^{(h)}, s^{(h)}\right\}_{h=0}^{H}\right)}{\partial p^{(0)}}=0$, the decentralized equilibrium is constrained efficient, i.e., $\mathbf{x}(D, D, s)=\mathbf{x}^{S P}(D, s)$.

Proof. See Appendix A.

The theorem argues that under fairly general conditions, economies that feature borrowing constraints that do not depend on current prices are constrained-efficient. In particular, the two necessary conditions are (i) non-decreasing effects of prices in collateral, and (ii) differentiability of the constraint. Condition (i) holds in the current-income constraint (3) and the future-income-constraint (4). Condition (ii) is satisfied in constraint (3) but not in (4). However, we show in Appendix A that the result in Theorem 4 also holds for constraint $4 .^{4}$

To understand the efficiency result, it is useful to consider the Euler equation of the social planner's problem (SP) in the future-income-collateral economy, which is given by

$$
u_{\mathrm{T}}\left(c^{\mathrm{T}}, c^{\mathrm{N}}\right)=\beta R \mathbb{E}\left[u_{T}\left(c^{\mathrm{T}^{\prime}}, c^{\mathrm{N}^{\prime}}\right)\right]+\mu^{S P}\left[1-\frac{\partial \bar{d}\left(p^{(1)}, s^{(1)}\right)}{\partial p^{(1)}} \frac{\partial \mathcal{P}\left(D^{\prime}, s^{\prime}\right)}{\partial D^{\prime}}\right]
$$

Comparing this condition with the Euler equation (5) from the competitive equilibrium, we can construct the following mapping between the Lagrange multipliers of the borrowing constraint in both problems, $\mu=\mu^{S P}\left[1-\frac{\partial \bar{d}\left(p^{(1)}, s^{(1)}\right)}{\partial p^{(1)}} \frac{\partial \mathcal{P}\left(D^{\prime}, s^{\prime}\right)}{\partial D^{\prime}}\right]$. Since collateral is decreasing in aggregate debt (i.e., $\frac{\partial \bar{d}\left(p^{(1)}, s^{(1)}\right)}{\partial p^{(1)}} \frac{\partial \mathcal{P}\left(D^{\prime}, s^{\prime}\right)}{\partial D^{\prime}}<0$, as shown in the proof), this implies that the shadow value of relaxing the borrowing constraint in the social planner problem's is a rescaled version of its competitive equilibrium counterpart.

In the current-income-collateral economy, the social planner's Euler equation is given

\footnotetext{
${ }^{4}$ We show this by expressing constraint (4) as $K$ differentiable constraints, and also showing that the result extends to the general case with $K$ differentiable constraints.
} 


$$
u_{\mathrm{T}}\left(c^{\mathrm{T}}, c^{\mathrm{N}}\right)=\beta R \mathbb{E}\left[u_{T}\left(c^{\mathrm{T}^{\prime}}, c^{\mathrm{N}^{\prime}}\right)\right]+\beta R \mathbb{E}\left[\Psi^{\prime} \mu^{S P^{\prime}}\right]+\mu^{S P}
$$

where $\Psi=\frac{\partial \bar{d}\left(\left\{p^{(h)}, s^{(h)}\right\}_{h=0}^{H}\right)}{\partial p^{(0)}} \frac{\partial\left(\frac{A_{N}\left(c^{\mathrm{T}}, c^{\mathrm{N}}\right)}{A_{T}\left(c^{\mathrm{T}}, c^{\mathrm{N}}\right)}\right)}{\partial c^{\mathrm{T}}}$, which implies that there is no scaling of multipliers. In fact, when the current borrowing constraints are slack in both problems (i.e., $\mu=\mu^{S P}=0$ ), the social planner may still want to distort the Euler equation by taxing borrowing, which increases next period's tradable consumption and relaxes the future constraint. In the futureincome-collateral economy, this type of policy is not possible because collateral is decreasing in aggregate borrowing. Relaxing next-period constraint by increasing collateral values would require increasing tradable consumption two periods from now, which in turn, in the absence of commitment, can only be achieved by saving more in the next period. This contradicts the original intention of increasing borrowing in the next period if the constraint binds.

We conclude from this analysis that the source of inefficiency lies in the relationship between aggregate borrowing and collateral values. In the current-income-collateral economy, by borrowing more, the economy increases current consumption and collateral values. In the future-income-collateral economy, higher aggregate borrowing leads to lower future consumption, and thus lower collateral values. Therefore, unless collateral is determined by current prices, the planner cannot exploit this feedback, which is what gives rise to the inefficiency.

\section{The Challenge of Distinguishing Between Models}

In this section, we discuss why it would be hard for a researcher to determine whether credit markets are characterized by current-income collateral constraints, which lead to inefficiencies, or future-price collateral constraints, which do not lead to inefficiencies. Section 4.1 compares the microfoundations of these two models and Section 4.2 discusses their quantitative properties. Finally, Section 4.3 quantifies the welfare implications of model misspecification. 


\subsection{Microfoundations}

Future-income collateral constraints. The future-income collateral constraint (4) can be derived from an environment with the following assumptions.

i. Borrowers lack commitment and can default in the repayment period.

ii. If borrowers default, lenders can seize a fraction $\kappa(s)$ of the borrower's income. Borrowers receive no other punishment from default. (They retain full access to credit markets in the event of default.)

iii. Lenders are only willing to offer risk-free contracts. (That is, lenders have sufficiently large costs from default.)

This type of commitment friction is similar to that used by Eaton and Gersovitz (1981), with the variant that lenders perceive the cost of default and can seize a fraction of income in that event.

In this setup, the value of repayment for a household, $V^{R}(d, D, s)$, is given by

$$
\begin{gathered}
V^{R}(d, D, s)=\max _{c^{\mathrm{T}}, c^{\mathrm{N}}, d^{\prime}} u\left(A\left(c^{\mathrm{T}}, c^{\mathrm{N}}\right)\right)+\beta \mathbb{E}\left[\max \left\{V^{R}\left(d^{\prime}, D^{\prime}, s^{\prime}\right), V^{D}\left(D^{\prime}, s^{\prime}\right)\right\}\right] \\
\text { subject to } c^{\mathrm{T}}+p(D, s) c^{\mathrm{N}}+d=q\left(d^{\prime}, D, s\right) d^{\prime}+y^{\mathrm{T}}+p(D, s) y^{\mathrm{N}} \\
D^{\prime}=\mathcal{D}(D, s), \quad \Gamma\left(s^{\prime}, s\right)
\end{gathered}
$$

where $q\left(d^{\prime}, D, s\right)$ denotes the debt price schedule, taken as given by the household, and $V^{D}(D, s)$ denotes the value of default, given by

$$
\begin{array}{ll} 
& V^{D}(D, s)=\max _{c^{\mathrm{T}}, c^{\mathrm{N}}, d^{\prime}} u\left(A\left(c^{\mathrm{T}}, c^{\mathrm{N}}\right)\right)+\beta \mathbb{E}\left[\max \left\{V^{R}\left(d^{\prime}, D^{\prime}, s^{\prime}\right), V^{D}\left(D^{\prime}, s^{\prime}\right)\right\}\right] \\
\text { subject to } \quad & c^{\mathrm{T}}+p(D, s) c^{\mathrm{N}}=q\left(d^{\prime}, D, s\right) d^{\prime}+(1-\kappa)\left(y^{\mathrm{T}}+p(D, s) y^{\mathrm{N}}\right), \\
& D^{\prime}=\mathcal{D}(D, s), \quad \Gamma\left(s^{\prime}, s\right) .
\end{array}
$$

From (8) and (9), it follows that borrowers repay in a state $(d, D, s)$ if and only if their level 
of borrowing $d$ does not exceed the level of income seized by lenders:

$$
d \leq \kappa(s)\left(y^{\mathrm{T}}(s)+p(D, s) y^{\mathrm{N}}(s)\right)
$$

If lenders are only willing to offer debt contracts in which the borrower does not default, this means that in a given state $(D, s)$, lenders will only be willing lend up to a fraction of the lowest possible income level denominated in units of tradables, implying that

$q\left(d^{\prime}, D, s\right)=\left\{\begin{array}{cc}\frac{1}{R} \quad \text { if } \quad d^{\prime} \leq \min _{s^{\prime} \mid s} \kappa(s)\left(y^{\mathrm{T}}\left(s^{\prime}\right)+p\left(D^{\prime}, s^{\prime}\right) y^{\mathrm{N}}\left(s^{\prime}\right)\right) \\ 0 \quad \text { if } \quad d^{\prime}>\min _{s^{\prime} \mid s} \kappa(s)\left(y^{\mathrm{T}}\left(s^{\prime}\right)+p\left(D^{\prime}, s^{\prime}\right) y^{\mathrm{N}}\left(s^{\prime}\right)\right),\end{array}\right.$ which is equivalent to (4).

Current-income collateral constraints. Microfoundations of collateral constraint (3) can be found, for instance, in Bianchi and Mendoza (2018), with an agency problem similar to the one described above but with the following modifications:

i. Default by borrowers requires fraud in the borrowing period.

ii. The fraud can be perfectly observed by lenders. If lenders observe fraud they can seize a fraction $\kappa(s)$ of current income.

Given this assumed fraud technology and punishments, lenders will be willing to lend up to a fraction of the borrower's current income, as in constraint (3).

We conclude from this discussion that, on the grounds of microfoundations, it is hard to argue that an economy features the current-income-collateral agency problem and not that of future-income collateral.

\subsection{Quantitative properties}

We now show that it would also be hard for a researcher to distinguish between the current and future-income-constraint models based on their quantitative aggregate predictions.

Current-income-constraint model. Our benchmark for the current-income collateralconstraint model is the calibration in Bianchi (2011) for Argentina, which shows how this 
Table 1: Fixed Parameters

\begin{tabular}{lcc}
\hline \hline \multicolumn{1}{c}{ Description } & Parameter & Value \\
\hline (a) Preferences & & \\
Interest rate & $R$ & 1.04 \\
Coefficient of relative risk aversion & $\xi$ & 2 \\
Intratemporal elasticity of substitution & & 0.83 \\
(b) Endowment processes & $\sigma_{T}$ & 0.047 \\
Standard deviation shocks to tradable endowment & $\sigma_{N}$ & 0.041 \\
Standard deviation shocks to nontradable endowment & $\sigma_{T N}$ & 0.842 \\
Covariance shocks to tradable and nontradable endowment & $\rho_{T}$ & 0.901 \\
Autocorrelation of tradable endowment & $\rho_{N}$ & 0.225 \\
Autocorrelation of nontradable endowment & $\rho_{T N}$ & 0.495 \\
Cross-correlation of tradable endowment & $\rho_{N T}$ & -0.453 \\
Cross-correlation of nontradable endowment & & \\
\hline \hline
\end{tabular}

Notes: This table shows the subset of parameters that are fixed in the calibration.

model can reproduce key emerging-market business-cycle patterns.

Regarding functional forms, this calibration assumes a constant-relative-risk-aversion utility function, $u(c)=\frac{c^{1-\sigma}-1}{1-\sigma}$, and a constant-elasticity-of-substitution (CES) aggregation technology for tradable and nontradable goods, $C\left(c_{t}^{\mathrm{T}}, c_{t}^{\mathrm{N}}\right)=\left[a\left(c_{t}^{\mathrm{T}}\right)^{1-\frac{1}{\xi}}+(1-a)\left(c_{t}^{\mathrm{N}}\right)^{1-\frac{1}{\xi}}\right]^{\frac{\xi}{\xi-1}}$. These functional forms imply that the model features four parameters related to preferences, $\{\beta, \sigma, \xi, a\}$. In addition, it is assumed that the endowment processes follow a first-order au-

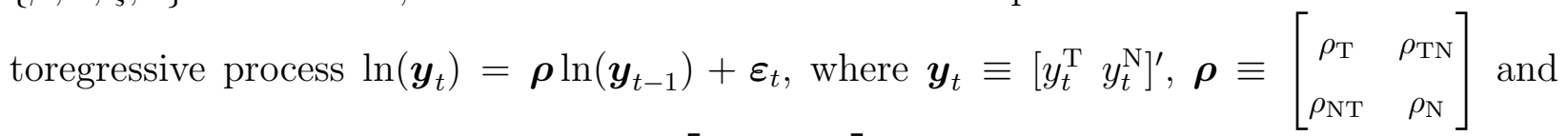
$\varepsilon_{t} \equiv\left[\varepsilon_{t}^{\mathrm{T}} \varepsilon_{t}^{\mathrm{N}}\right]^{\prime} \sim$ i.i.d. $N(\emptyset, \Omega)$, with $\Omega \equiv\left[\begin{array}{cc}\sigma_{\mathrm{T}}^{2} & \sigma_{\mathrm{TN}} \\ \sigma_{\mathrm{TN}} & \sigma_{\mathrm{N}}^{2}\end{array}\right]$.

We calibrate the model to an annual frequency. The parameterization of the model is then conducted in two steps. The first step consists of exogenously fixing the values of 10 parameters, which either have standard values or estimates or can be estimated directly. These parameters are reported in Table 1 and directly follow Bianchi (2011). The inverse of the intertemporal elasticity of substitution is set to $\sigma=2$, the intratemporal elasticity of substitution to $\xi=0.83$, and the risk-free rate to $R=1.04$. For the stochastic processes of tradable and nontradable endowment, the parameters were estimated based on Argentinean data on sectoral value added from WDI for the period 1965 to 2007. 
Table 2: Targeted Moments

\begin{tabular}{lccc}
\hline \hline & Data & Current Income & Future Income \\
\hline Share of tradable output & $0.32 \%$ & $0.32 \%$ & $0.32 \%$ \\
Average NFA-GDP ratio & $-29 \%$ & $-30.5 \%$ & $-29.2 \%$ \\
Frequency of crises & $5.5 \%$ & $5.86 \%$ & $5.65 \%$ \\
\hline \hline
\end{tabular}

Notes: This table shows the model counterparts of three targeted moments. It compares the values implied by the current-income-constraint model with those implied by the future-income-constraint model. The set of targeted moments includes the share of tradable output, the average net financial asset position, and the frequency of crises as defined in the main text.

The second step of the parameterization consists of choosing the model's three remaining parameters, $\{\beta, \kappa, a\}$, to match key moments in the ergodic distributions of the model to those observed in historical Argentinean data. The targeted moments are reported in Table 2. The first two targeted moments, which are mostly governed by $\beta$ and $\kappa$, are the average debt position (-29\% in Argentinean data) and the frequency of sudden stops (5.5\% in Eichengreen et al. (2008) for a sample of emerging economies). ${ }^{5}$ The third empirical target is the share of tradable output in GDP (32\% in Argentinean data), which is mostly governed by the preference parameter in the CES aggregator between tradable and nontradable goods, $a$. Table 2 shows that the calibrated economy closely approximates the empirical targets. Table 3 shows the value of calibrated parameters.

Table 4 shows that the model's business-cycle patterns are close to those observed in the data for untargeted moments. In particular, the range of model predictions for the volatility of consumption, the real exchange rate, the current account, and the trade balance are in line with those in the data. In addition, the model predicts a countercyclical trade balance and real exchange rates, which are an important dimension of emerging-market business cycles and are also observed for Argentina (see, for example, Aguiar and Gopinath (2007)). Figures B.1 and B.2 in Appendix B.1 depict the equilibrium debt policy functions.

\footnotetext{
${ }^{5}$ The frequency for emerging economies is similar to the frequency for Argentina during this period. Regarding the definition of a sudden stop in the model, we follow Bianchi (2011) and define it as an event in which the collateral constraint binds, leading to net capital outflows that exceed one standard deviation.
} 
Table 3: Calibrated Parameters

\begin{tabular}{lccc}
\hline \hline & Parameter & Current Income & Future Income \\
\hline Weight on Tradables in CES & $\omega$ & 0.31 & 0.31 \\
Subjective Discount Factor & $\beta$ & 0.91 & 0.94 \\
Credit Regime & $\kappa$ & 0.32 & 0.30 \\
\hline \hline
\end{tabular}

Notes: This table shows the subset of parameters calibrated to match targeted moments; see Table 2.

Table 4: Business-cycle Moments

\begin{tabular}{lccc}
\hline \hline & Data & Current Income & Future Income \\
\hline Standard deviations & & & \\
Consumption & 6.2 & 5.61 & 4.62 \\
Real Exchange Rate & 8.2 & 8.05 & 6.2 \\
Current Account-GDP & 3.6 & 2.41 & 1.32 \\
Trade Balance-GDP & 2.4 & 2.54 & 1.39 \\
& & & \\
Correlations with GDP & & & \\
Consumption & 0.88 & 0.94 & 0.88 \\
$\quad$ Real Exchange Rate & 0.41 & 0.95 & 0.91 \\
$\quad$ Current Account-GDP & -0.63 & -0.54 & -0.17 \\
$\quad$ Trade Balance-GDP & -0.84 & -0.55 & -0.28 \\
\hline Average NFA-GDP Ratio & $-29 \%$ & $-30.4 \%$ & $-29.2 \%$ \\
Frequency of Sudden Stops & $5.5 \%$ & $5.86 \%$ & $5.65 \%$ \\
Prob( $\mu>0)$ & - & $14.68 \%$ & $12.71 \%$ \\
\hline \hline
\end{tabular}

Notes: This table shows untargeted second moments regarding business cycles and their model counterparts, obtained by simulating the calibrated model. The table compares the values implied by the current-incomeconstraint model with those implied by the future-income-constraint model. $\operatorname{Prob}(\mu>0)$ denotes the probability that the borrowing constraint binds. Correlations with GDP refer to correlations with GDP in units of tradables.

Future-income-constraint model We follow a similar calibration for the future-incomeconstraint model. One important exception is that to generate business-cycle patterns aligned with those observed in the emerging markets' data, the future-income-constraint model requires some variation in the level of income that can be pledged as collateral, $\kappa(s) .{ }^{6}$ The reason for this is simple: Given that collateral is determined based on the minimum level of income a household can have (see equation 4), with a fixed share of income pledged as

\footnotetext{
${ }^{6}$ These types of shocks have been used in the literature to capture sudden stops driven by shocks to foreign investors' confidence in EMs (see, for example, Benigno and Fornaro (2012); Morelli et al. (2019)). See also Khan and Thomas (2013) and Guerrieri and Lorenzoni (2017) for a similar application to the Great Recession.
} 
collateral $\kappa$, it would be hard for this model to generate fluctuations in collateral that are critical for generating sudden stops in collateral-constraint models (see Korinek and Mendoza (2014)). In fact, in Appendix B.2 we show that if the model with future-income constraints is calibrated with a time-invariant $\kappa$, the economy does not feature a countercyclical trade balance or sudden stops, which are an important element observed in the data.

To calibrate the shocks to the share of income that can be pledged as collateral, we assume that $\kappa(s)$ follows a first-order Markov process. As is standard in the literature using these shocks, we assume for simplicity that $\kappa(s) \in\{\kappa, \bar{\kappa}\}$, with $\kappa<\bar{\kappa}$. The value of $\bar{\kappa}$ is set to an arbitrarily high value such that the collateral constraint never binds if $\kappa(s)=\bar{\kappa}$. Similar to the baseline calibration, the parameters $\{\beta, a, \kappa\}$ are used to match the average external debt-to-GDP ratio, the share of tradable output in GDP, and the frequency of sudden stops observed in the data. Following Benigno and Fornaro (2012), the probability of entering a low-collateral-constraint state, denoted $\pi_{\kappa}$, is set to 0.1 (Jeanne and Rancière (2011)), and the probability of exiting a low-collateral-constraint state, denoted $\pi_{\bar{\kappa}}$, is set to 0.5 (Alfaro and Kanczuk (2009)). The other parameters are set to the exact same value as in the calibration for the model with current income as collateral (Table 1).

Figures B.3 and B.4 in Appendix B.1 depict the equilibrium debt policy functions. Table 4 shows that the calibrated future-income-collateral model generates business-cycle moments similar to those of the current-income-collateral model and to those observed in the data. In particular, the model is also able to generate a countercyclical current account and excess volatility of consumption.

We also assess the ability of both models to reproduce the macroeconomic dynamics during episodes of sudden stops. In the model, we identify sudden stop episodes as periods when (i) the collateral constraint is binding and (ii) the current account is at least one standard deviation above its steady-state average. In the data, we consider the sudden stops of 1982, 1990, 1995, and 2002 identified by Korinek and Mendoza (2014). Figure 1 shows that both models can account for the emprical regularities observed in the data during episodes of sudden stops: An increase in the current account at the onset of the crisis, a depreciation of the real exchange rate, and a significant drop in both consumption and output. We therefore 
conclude that from the perspective of aggregate data, it is also hard for a researcher to determine whether the observed patterns in the data are generated by a current-incomecollateral model or a future-income-collateral model.

Figure 1: Crisis Dynamics: Current- and Future-Income Models
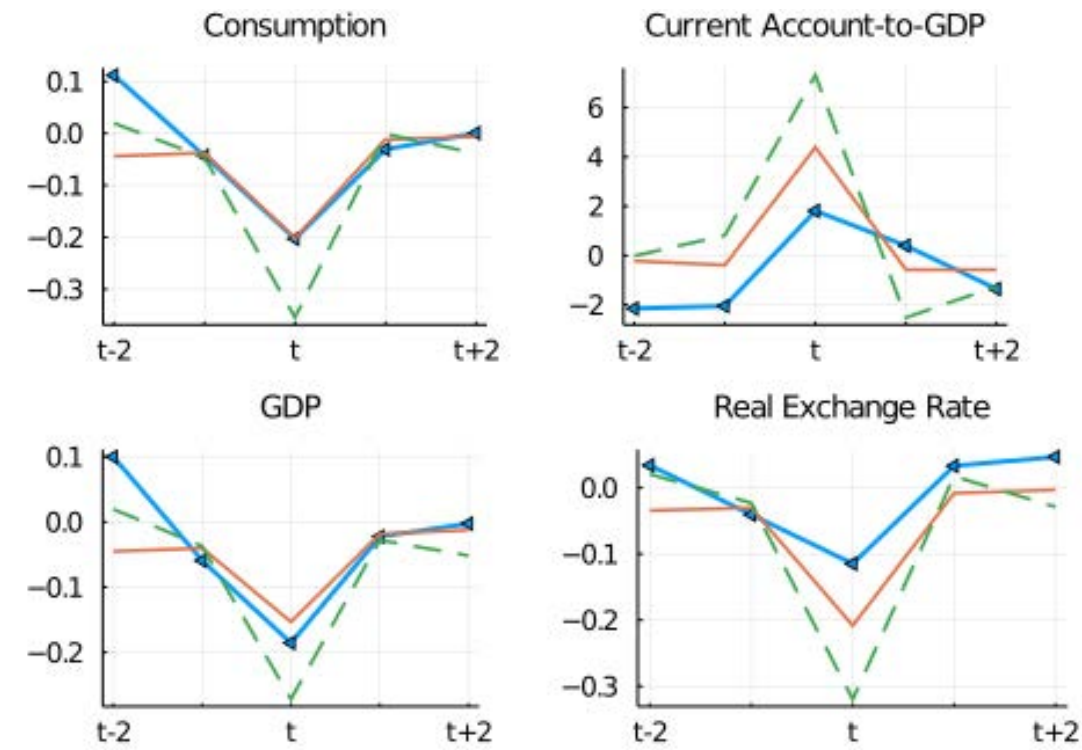

Notes: This figure plots aggregate dynamics during the typical sudden stop episode in the data (blue solid line), in the current-income model (green dashed line) and in the future-income model (solid red line). Data values are obtained by taking averages across four sudden stop events in 1982, 1990, 1995 and 2002 . In the model, a crisis episode is defined as a period in which (i) the collateral constraint binds and (ii) the current account is at least one standard deviation above its steady-state average. In the model, consumption, GDP, and the real exchange rate are expressed in log-deviations from their ergodic means; the current accountto-GDP ratio is expressed in levels. Consumption and GDP are measured in units of tradables in both the data and the model.

\subsection{The Welfare Costs of Model Misspecification in Policy Design}

In this section, we study the welfare costs of model specification in policy design. Two possible errors in policy design stem from model misspecification. The first error is to not implement macroprudential policies and act as if the economy faces future-income collateral when, in fact, the economy faces current-income collateral and borrowing is inefficient. The 
Table 5: Welfare Costs of Model Misspecification

\begin{tabular}{lcc}
\hline \hline & $\begin{array}{c}\text { Current Income } \\
\text { without Taxes }\end{array}$ & $\begin{array}{c}\text { Future Income } \\
\text { with Taxes }\end{array}$ \\
\hline Average Welfare Loss & $0.088 \%$ & $0.007 \%$ \\
Standard Deviation of Welfare Losses & $0.014 \%$ & $0.002 \%$ \\
Correlation of Welfare Losses with GDP & -0.420 & -0.392 \\
\hline \hline
\end{tabular}

Notes: The first column reports welfare losses from not implementing optimal capital-control taxes in the current-income-constraint economy. The second column reports welfare losses from implementing those capital-control taxes in the future-income-constraint economy. Moments in the first (second) column are computed based on the ergodic distribution in the constrained-efficient equilibrium of the current-(future-) income-constraint economy .

second error is to design macroprudential policies aimed at correcting inefficiencies from a current-income-collateral model when, in fact, the economy faces future-income-collateral constraints and borrowing is not inefficient.

We quantify these costs and express them as consumption-equivalent deviations from the efficient allocation in the relevant economy. We formally define these costs in Appendix B.3. Table 5 shows key statistics of both types of welfare costs, with two main conclusions. First, the welfare costs of not taxing an economy with current-income collateral are not negligible $-0.09 \%$ on average - which suggests that obtaining direct evidence to ensure the presence of current-income collateral can have large benefits for policymakers interested in implementing macroprudential policies. These costs are countercyclical, since the macroprudential nature of policies prevents the economy from borrowing when income starts contracting, and households would prefer to smooth consumption. ${ }^{7}$ The second conclusion is that the average welfare costs of taxing an economy with future-income collateral appear to be an order of magnitude smaller than the opposite type of error. In this sense, policymakers who assign equal probability to both types of model would tend to prefer to implement macroprudential policies even in the absence of full certainty that they live in an economy with borrowing inefficiencies.

Finally, Table B.4 in Appendix B.3 shows that implementing optimal taxes derived from the economy with current-income collateral in either of the two economies reduces the

\footnotetext{
${ }^{7}$ Figures B.5 and B.6 in Appendix B.3 show the histogram of welfare losses evaluated at the ergodic distribution of simulated states.
} 
frequency of sudden stops. In this sense, the prediction that macroprudential policies insulate the economy from crises holds in both types of economies.

\section{Extensions}

\subsection{Optimal Policy under Commitment}

In this section, we study the optimal policy under the alternative assumption that the social planner has the ability to commit to future policies. Rather than taking future policies as given, the planner now chooses once and for all the entire state-contingent sequence of consumption and debt, given an initial condition. The Ramsey problem of the planner is given by

$$
\begin{array}{cl}
\max _{\left\{c_{t}^{T}\left(s^{t}\right), D_{t+1}\left(s^{t}\right)\right\}} \mathbb{E}_{0} \sum_{t=0}^{\infty} \beta^{t} u\left(A\left(c_{t}^{T}\left(s^{t}\right), y_{t}^{N}\left(s^{t}\right)\right)\right) \\
\text { subject to } \quad c_{t}^{T}\left(s^{t}\right)=y_{t}^{T}\left(s^{t}\right)+D_{t+1}\left(s^{t}\right)-R D_{t}\left(s^{t-1}\right), \\
D_{t+1}\left(s^{t}\right) \leq \bar{d}\left(\left\{p_{t+h}\left(c_{t+h}^{T}\left(s^{t+h}\right), y_{t+h}^{N}\left(s^{t+h}\right)\right), s^{t+h}\right\}_{h=0}^{H}\right), \\
p_{t}\left(c_{t}^{T}\left(s^{t}\right), y_{t}^{N}\left(s^{t}\right)\right)=\frac{A_{N}\left(c_{t}^{\mathrm{T}}\left(s^{t}\right), y_{t}^{\mathrm{N}}\left(s^{t}\right)\right)}{A_{T}\left(c_{t}^{\mathrm{T}}\left(s^{t}\right), y_{t}^{\mathrm{N}}\left(s^{t}\right)\right)}
\end{array}
$$

for a given $D_{0}\left(s^{-1}\right)$. The maximization is subject to three implementability conditions: the resource constraint, the collateral constraint, and the equilibrium price function.

For expositional simplicity, we focus here on the case in which the collateral constraint can depend only on the current price and/or on the price one period ahead, which corresponds to setting $H=1$. Suppose that at time $t$ the borrowing constraint is not currently binding 
under the optimal policy. Then the Euler equation of the social planner is given by

$$
\begin{aligned}
u_{\mathrm{T}}\left(c_{t}^{T}, y_{t}^{N}\right) & =R \beta \mathbb{E}_{t} u_{\mathrm{T}}\left(c_{t+1}^{T}, y_{t+1}^{N}\right) \underbrace{-\mu_{t-1}^{S P} \frac{\partial \bar{d}\left(\left\{p_{t-1}, p_{t}\right\}\right)}{\partial p_{t}} \frac{\partial p_{t}\left(c_{t}^{T}, y_{t}^{N}\right)}{\partial c_{t}^{T}}}_{\text {forward guidance }} \\
& +\underbrace{R \beta \mathbb{E}_{t} \mu_{t+1}^{S P} \frac{\partial \bar{d}\left(\left\{p_{t+1}, p_{t+2}\right\}\right)}{\partial p_{t+1}} \frac{\partial p_{t+1}\left(c_{t+1}^{T}, y_{t+1}^{N}\right)}{\partial c_{t+1}^{T}}}_{\text {macro-prudential }},
\end{aligned}
$$

where $\mu_{t-1}^{S P}$ and $\mu_{t+1}^{S P}$ denote the Lagrange multipliers on the collateral constraint at time $t-1$ and $t+1$. This expression shows that the Euler equation of the social planner does not coincide in general with the Euler equation of the private agents in the competitive equilibrium. The wedge between the two is given by the sum of two parts: a "forward guidance" term that involves lagged multipliers and a "macroprudential" term that involves future multipliers.

In the current-income model, $\frac{\partial \bar{d}\left(\left\{p_{t}, p_{t+1}\right\}\right)}{\partial p_{t+1}}=0$, which makes the forward guidance term equal to zero and the Euler equation of the social planner becomes the same as in Bianchi (2011). We therefore recover the result in which the planner optimally taxes borrowing whenever the collateral constraint becomes binding at $t+1$ with positive probability. Notice that the Euler equation of the planner does not feature lagged multipliers, if only current income is used as collateral. It follows that in this case, the optimal policy under commitment is in fact time consistent.

In the future-income model, by contrast, $\frac{\partial \bar{d}\left(\left\{p_{t}, p_{t+1}\right\}\right)}{\partial p_{t}}=0$ and the macroprudential term is equal to zero. Hence, the only wedge in the planner's Euler equation comes from the forward guidance term, which is negative if the collateral constraint binds at time $t-1$. This term captures the fact that an increase in borrowing at time $t$ relaxes the collateral constraint at time $t-1$. The planner internalizes this effect, and hence promises a debt subsidy in the period after the collateral constraint binds. This stands in contrast to the policy of taxing debt accumulation prior to periods of crisis, which is optimal in models in which current income affects collateral. It is worth noting that the optimal policy is not time consistent, since the planner's Euler equation features lagged multipliers when future prices enter the constraint. 
To conclude, the following result formalizes the result whereby, when only future prices affect collateral, the planner optimally implements a debt subsidy after episodes of binding collateral constraint.

Theorem 2. If $H=1$ and for all $t \frac{\partial \bar{d}\left(\left\{p_{t+h}, s^{t+h}\right\}\right)}{\partial p_{t}}=0$, the optimal policy under commitment can be decentralized via state-contingent subsidies on debt.

If the collateral constraint is not binding for the social planner at time $t-i . e ., \mu_{t}^{S P}=0-$ the optimal subsidy at time $t$ is given by

$$
\tau_{t}^{*}=-\frac{\mu_{t-1}^{S P} \frac{\partial \bar{d}\left(\left\{p_{t-1}, p_{t}\right\}\right)}{\partial p_{t}} \frac{\partial p_{t}\left(c_{t}^{T}, y_{t}^{N}\right)}{\partial c_{t}^{T}}}{R \beta E_{t} u_{\mathrm{T}}\left(c_{t+1}^{T}, y_{t+1}^{N}\right)} \leq 0 .
$$

\subsection{Model with capital}

This section extends our efficiency result in models in which collateral constraints involve future prices to an environment in which capital instead of income is used as collateral.

\subsubsection{Environment}

For simplicity, we consider a single-sector economy with tradable goods and a fixed supply of capital. As in the baseline model, households' preferences over consumption are described by (1). Households have access to a technology to produce tradable goods using capital, $k_{t}\left(s^{t}\right)$, described by

$$
y_{t}\left(s^{t}\right)=z_{t}\left(s^{t}\right) k_{t}\left(s^{t}\right)^{\alpha}
$$

where $z_{t}\left(s^{t}\right)$ is an exogenous productivity factor that follows a Markov process and $\alpha \in(0,1)$. The household's budget constraint is given by

$$
c_{t}\left(s^{t}\right)+R d_{t}\left(s^{t-1}\right)+q_{t}\left(s^{t}\right)\left(k_{t+1}\left(s^{t}\right)-k_{t}\left(s^{t-1}\right)\right)=d_{t+1}\left(s^{t}\right)+y_{t}\left(s^{t}\right)
$$

where $q_{t}\left(s^{t}\right)$ denotes the price of one unit of capital and $\mathrm{R}$ is the exogenous interest rate on debt. We assume that debt cannot exceed a fraction $\kappa_{t}\left(s^{t}\right)$ of the market value of capital 
holdings in the period in which debt is repaid

$$
d_{t+1}\left(s^{t}\right) \leq \min _{q_{t+1}\left(s^{t+1} \mid s^{t}\right)}\left\{\kappa\left(s^{t}\right) q_{t+1}\left(s^{t+1}\right) k_{t+1}\left(s^{t}\right)\right\}
$$

This constraint is a stochastic version of the original formulation of Kiyotaki and Moore (1997), which, as discussed in Section 4.1, can be microfounded in an environment in which borrowers lack commitment and lenders can seize a fraction of their capital in the case of default. In open economies, a similar formulation has been studied in Devereux et al. (2019). ${ }^{8}$ Finally, note that this environment is similar to that considered in Bianchi and Mendoza (2018), except for the timing of the collateral constraint (12), which involves future prices and gives rise to the efficiency of the competitive equilibrium.

\subsubsection{Competitive Equilibrium}

We express the household's problem recursively. The household's idiosyncratic state is given by the vector $\mathbf{s}=(d, k, D, s)$, where $d$ and $k$ are the idiosyncratic household's levels of debt and capital, $D$ is the aggregate level of debt, and $s$ is the exogenous state - which includes the productivity shock and the shock to the fraction of capital that can be pledged as collateral. The household's optimization problem is

$$
\begin{array}{ll} 
& V(\mathbf{s})=\max _{c, d^{\prime}, k^{\prime}} u(c)+\beta \mathbb{E}\left[V\left(\mathbf{s}^{\prime}\right)\right] \\
\text { subject to } \quad & c+R d+q(D, s)\left(k^{\prime}-k\right)=d^{\prime}+z k^{\alpha}, \\
& d^{\prime} \leq \kappa \min _{\mathbf{s}^{\prime}} q\left(D^{\prime}, s^{\prime}\right) k^{\prime}, \\
D^{\prime}=\mathcal{D}(D, s), \quad \Gamma\left(s^{\prime}, s\right),
\end{array}
$$

where $q(D, s)$ is the asset price function, $\mathcal{D}(D, s)$ the conjecture for the aggregate debt law of motion, and $\Gamma\left(s^{\prime}, s\right)$ the law of motion of the exogenous state.

Solving the maximization problem and using the fact that capital is in unitary supply

\footnotetext{
${ }^{8}$ In contrast to our efficiency result, Devereux et al. (2019) find scope for macroprudential policies. This is because their model includes additional elements that our analysis abstracts from, such as nominal rigidities and working capital financing requirements.
} 
yields the following optimality conditions:

$$
\begin{gathered}
u^{\prime}(c)=\beta R \mathbb{E} u^{\prime}\left(c^{\prime}\right)+\mu, \\
q(D, s) u^{\prime}(c)=\mathbb{E}\left[\beta\left(z^{\prime}+q\left(D^{\prime}, s^{\prime}\right)\right) u^{\prime}\left(c^{\prime}\right)\right]+\mu \kappa \min _{\mathbf{s}^{\prime}}\left\{q\left(D^{\prime}, s^{\prime}\right)\right\},
\end{gathered}
$$

where $\mu \geq 0$ is the Lagrange multiplier associated with constraint (12), with the complementary slackness condition, $\mu\left(\min _{\mathbf{s}^{\prime}} q\left(D^{\prime}, s^{\prime}\right) k^{\prime}-d^{\prime}\right)=0$.

We define a recursive competitive equilibrium as follows:

Definition 3. A recursive competitive equilibrium is a set of policy functions $\mathbf{x}(\mathbf{s}) \equiv$ $\left\{c(\mathbf{s}), d^{\prime}(\mathbf{s}), k^{\prime}(\mathbf{s})\right\}$, a price function $q(D, s)$, and a conjecture policy $\mathcal{D}(D, s)$ such that

1. Policy functions solve household's problem ( $\left.\mathrm{P}^{\prime}\right)$.

2. Markets clear, $c=y+d^{\prime}-R d$ and $k^{\prime}=1$.

3. Conjectures are consistent with the policy functions, $\mathcal{D}(D, s)=d^{\prime}(D, 1, D, s)$.

\subsubsection{Constrained Efficiency}

We introduce the notion of constrained efficiency along the same lines as in Section 3. We consider the problem of a social planner who can tax household borrowing and lacks commitment. The planner's optimization problem is given by

$$
W(D, s)=\max _{c, D^{\prime}, q, \mu} u(c)+\beta \mathbb{E}\left[W\left(D^{\prime}, s^{\prime}\right)\right]
$$

subject to

$$
\begin{aligned}
& c+R D=z+D^{\prime}, \\
& D^{\prime} \leq \kappa \min _{s^{\prime}}\left\{\mathcal{Q}\left(D^{\prime}, s^{\prime}\right)\right\}, \\
& q u^{\prime}(c)=\beta \mathbb{E}\left[\left(\alpha z^{\prime}+\mathcal{Q}\left(D^{\prime}, s^{\prime}\right)\right) u^{\prime}\left(\mathcal{C}\left(D^{\prime}, s^{\prime}\right)\right)\right]+\mu \kappa \min _{s^{\prime}}\left\{\mathcal{Q}\left(D^{\prime}, s^{\prime}\right)\right\}, \\
& \mu\left[D^{\prime}-\kappa \min _{s^{\prime}}\left\{\mathcal{Q}\left(D^{\prime}, s^{\prime}\right)\right\}\right]=0, \quad \mu \geq 0,
\end{aligned}
$$


where $\mathcal{C}(D, s)$ and $\mathcal{Q}(D, s)$ are the planner's conjectures of future consumption and price of capital policies. The first two restrictions are, respectively, the economy resource constraint and the collateral constraint. The third is the equilibrium expression for the price of capital, and the last restriction includes the complementary slackness and nonnegativity conditions for the competitive equilibrium multiplier.

A constrained-efficient equilibrium is defined as follows:

Definition 4. A constrained-efficient allocation is a set of policy functions $\mathbf{x}^{S P}(D, s) \equiv$ $\left\{c(D, s), D^{\prime}(D, s)\right\}$ and conjectured policies $\mathcal{D}(D, s)$ and $\mathcal{Q}(D, s)$ such that

1. Policy functions solve the planner's problem (SP').

2. Conjectures are consistent with policy functions, $\mathcal{D}(D, s)=D^{\prime}(D, s)$ and $q(D, s)=$ $\mathcal{Q}(D, s)$.

Similar to the model with income-based collateral, we now provide conditions under which the competitive equilibrium is constrained-efficient.

Theorem 3. Consider a decentralized equilibrium in which $\left(1-\kappa \frac{\partial \min _{s} q(D, s)}{\partial D}\right)>0$ for all $D$. Then the decentralized equilibrium is constrained-efficient, i.e., $\left\{c(D, 1, D, s), d^{\prime}(D, 1, D, s)\right\}=$ $\mathbf{x}^{S P}(D, s)$.

The condition of $\left(1-\kappa \frac{\partial \min _{s} q(D, s)}{\partial D}\right)>0$ used in the theorem imposes an upper bound on the response of the price of capital to increases in aggregate debt. This condition usually holds in quantitative versions of this type of models (see, for example, Devereux et al., 2019).

To understand the intuition behind Theorem 3, consider the Euler equation of the social planner:

$$
u^{\prime}(c)=\beta R \mathbb{E} u^{\prime}\left(c^{\prime}\right)+\mu^{\mathrm{SP}}\left[1-\kappa \frac{\partial \min _{s^{\prime}}\left\{\mathcal{Q}\left(D^{\prime}, s^{\prime}\right)\right\}}{\partial D^{\prime}}\right] .
$$

Comparing this expression with the Euler equation of the competitive equilibrium allows us to derive the following mapping between both multipliers:

$$
\mu^{\mathrm{SP}}=\left[1-\kappa \frac{\partial \min _{s^{\prime}}\left\{\mathcal{Q}\left(D^{\prime}, s^{\prime}\right)\right\}}{\partial D^{\prime}}\right]^{-1} \mu .
$$


Provided that the term in brackets is positive - which the condition we impose in the theorem - this mapping ensures that the competitive equilibrium allocation solves the planner's optimality conditions, and hence is constrained-efficient.

\section{Conclusion}

Following the Great Recession, a large body of work arose that highlights how policymakers can use macroprudential policies over the business cycle as a tool to prevent financial crises. In emerging-market economies, in which these crises are frequent and severe, these policies found particularly fertile ground in the form of capital controls. In this paper, we show how the policy prescriptions of the current generation of quantitative models used to guide these policies critically depend on a specific form of collateral constraint that is linked to current rather than future prices. In any case, macroprudential policies do end up curbing borrowing and reducing the probability of financial crises. The question remains whether these restrictions on borrowing correct private-sector inefficiencies and improve welfare.

To address this question, future research that provides direct empirical evidence that characterizes borrowing contracts and shows how policies affect collateral, will be particularly relevant. For instance, in the field of monetary economics, large advances have been made in providing empirical evidence on the effect of monetary-policy shocks. This evidence has proven a useful input to disciplines critical aspects of the quantitative models used by policymakers (e.g., Romer and Romer (2004); Christiano et al. (2005); Nakamura and Steinsson (2018)). A similar body of work in the area of macroprudential policies would constitute an important guideline for quantitative models that can be used in the conduct of policy. Recent work by Chaney et al. (2012); Lian and Ma (2018); and Drechsel (2019), who study borrowing constraints in the corporate sector, constitute good steps toward this goal. 


\section{References}

Aguiar, M. and Gopinath, G. (2007). Emerging Market Business Cycles : The Cycle Is the Trend. Journal of Political Economy, 115 (1), 69-102.

Alfaro, L. and KanczuK, F. (2009). Optimal reserve management and sovereign debt. Journal of International Economics, 77 (1), 23-36.

Arora, V., Habermeier, K., Ostry, J. D. and Weeks-Brown, R. (2013). The liberalization and management of capital flows: An institutional view. Revista de Economía Institucional, 15 (28), 205-255.

Benigno, G., Chen, H., Otrok, C., Rebucci, A. and Young, E. R. (2013). Financial crises and macro-prudential policies. Journal of International Economics, 89 (2), 453-470.

- and Fornaro, L. (2012). Reserve Accumulation, Growth and Financial Crises, unpublished.

Bianchi, J. (2011). Overborrowing and systemic externalities in the business cycle. American Economic Review, 101 (7), 3400-3426.

- and Mendoza, E. G. (2018). Optimal Time-Consistent Macroprudential Policy. Journal of Political Economy, 126 (2), 588-634.

Chaney, T., Sraer, D. and Thesmar, D. (2012). The collateral channel: How real estate shocks affect corporate investment. American Economic Review, 102 (6), 2381-2409.

Chang, R. (1998). Credible monetary policy in an infinite horizon model: Recursive approaches. journal of economic theory, 81 (2), 431-461.

Chari, V. V. and Kenoe, P. J. (1990). Sustainable plans. Journal of political economy, 98 (4), 783-802.

Christiano, L. J., Eichenbaum, M. and Evans, C. L. (2005). Nominal rigidities and the dynamic effects of a shock to monetary policy. Journal of Political Economy, 113 (1), 1-45.

Devereux, M. B., Young, E. R. and Yu, C. (2019). Capital controls and monetary policy in sudden-stop economies. Journal of Monetary Economics, 103, 52-74.

Drechsel, T. (2019). Earnings-Based Borrowing Constraints and Macroeconomic Fluctuations, unpublished.

Eaton, J. and Gersovitz, M. (1981). Debt with Potential Repudiation: Theoretical and Empirical Analysis. The Review of Economic Studies, 48 (2), 289.

Eichengreen, B., Gupta, P. and Mody, A. (2008). Sudden stops and imf-supported programs. In Financial markets volatility and performance in emerging markets, University Of Chicago Press, pp. 219-266.

Farhi, E. and Werning, I. (2016). A Theory of Macroprudential Policies in the Presence of Nominal Rigidities. Econometrica, 84 (5), 1645-1704.

Fernández, A., Klein, M. W., Rebucci, A., Schindler, M. and Uribe, M. (2016). Capital control measures: A new dataset. IMF Economic Review, (64), 548-574.

Geanakoplos, J. D. and Polemarchakis, H. M. (1986). Existence, Regularity, and Constrained Suboptimality of Competitive Allocations When the Asset Market Is Incomplete. Uncertainty, information, and communication., Vol. 3, Essays in Honor of Kenneth J Arrow, ed. Walter P. Heller, Ross M. Starr and David A. Starrett, 65-95. New York: Cambridge University Press.

Guerrieri, V. and Lorenzoni, G. (2017). Credit crises, precautionary savings, and the liquidity trap. Quarterly Journal of Economics, 132 (3), 1427-1467.

Jeanne, O. and Rancière, R. (2011). The Optimal Level of International Reserves For Emerging Market Countries: A New Formula and Some Applications. Economic Journal, 121 (555), 905- 
930.

Kehoe, T. J. and Levine, D. K. (2001). Liquidity constrained markets versus debt constrained markets. Econometrica, 69 (3), 575-598.

Khan, A. and Thomas, J. K. (2013). Credit shocks and aggregate fluctuations in an economy with production heterogeneity. Journal of Political Economy, 121 (6), 1055-1107.

Kiyotaki, N. and Moore, J. (1997). Credit cycles. Journal of Political Economy, 105 (2), 211248.

Korinek, A. and Mendoza, E. G. (2014). From Sudden Stops to Fisherian Deflation: Quantitative Theory and Policy. Annual Review of Economics, 6 (1), 299-332.

LiAn, C. and MA, Y. (2018). Anatomy of Corporate Borrowing Constraints, unpublished.

Lorenzoni, G. (2008). Inefficient Credit Booms. The Review of Economic Studies, 75 (3), 809-833.

Mendoza, E. G. (2002). Credit, Prices, and Crashes: Business Cycles with a Sudden Stop. Preventing Currency Crises in Emerging Markets, NBER Conference Report series, ed. Sebastian Edwards and Jeffrey A. Frankel, 335-83. Chicago: University of Chicago Press.

Morelli, J. M., Ottonello, P. and Perez, D. J. (2019). Global banks and systemic debt crises, unpublished.

Nakamura, E. and Steinsson, J. (2018). High-frequency identification of monetary nonneutrality: the information effect. The Quarterly Journal of Economics, 133 (3), 1283-1330.

Romer, C. D. and Romer, D. H. (2004). A New Measure of Monetary Shocks: Derivation and Implications. American Economic Review, 94 (4), 1055-1084.

Schmitt-Grohé, S. and Uribe, M. (2016). Downward nominal wage rigidity, currency pegs, and involuntary unemployment. Journal of Political Economy, 124 (5), 1466-1514.

Schmitt-Grohé, S. and Uribe, M. (2021). Multiple equilibria in open economies with collateral constraints. Review of Economic Studies, 88 (4), 969-1001. 


\section{Appendices}

\section{A. Proofs and Additional Results}

\section{A.1. Lemmas}

For the proof of Theorem 1, we first introduce the following Lemma.

Lemma 1. If the consumption policy function of the decentralized equilibrium is non-increasing in debt, i.e., $\frac{\partial c^{\mathrm{T}}(D, s)}{\partial D} \leq 0$, and $\frac{\partial \bar{d}\left(\left\{p^{(h)}, s^{(h)}\right\}_{h=0}^{H}\right)}{\partial p^{(0)}}=0$, then the debt policy function of the decentralized equilibrium is non-decreasing in debt, i.e.,

$$
\frac{\partial d^{\prime}(D, s)}{\partial D} \geq 0
$$

Proof. Suppose that in state $\mathbf{s}=(D, s)$ the collateral constraint is binding. Using the assumption that $\frac{\partial \bar{d}\left(\left\{p^{(h)}, s^{(h)}\right\}_{h=0}^{H}\right)}{\partial p^{(0)}}=0$, we can write the collateral constraint as follows:

$$
D^{(1)}=\bar{d}\left(s,\left\{p\left(D^{(h)}, s^{(h)}\right), s^{(h)}\right\}_{h=1}^{H}\right), \quad \text { with } D^{(h+1)}=d^{\prime}\left(D^{(h)}, s^{(h)}\right) \quad \text { for } 1 \leq h \leq H .
$$

The debt policy, $d^{\prime}(D, s)$, is given by the value of $D^{(1)}$ that solves the above equation. Since $\frac{\partial \bar{d}\left(\left\{p^{(h)}, s^{(h)}\right\}_{h=0}^{H}\right)}{\partial p^{(0)}}=0$, the right-hand side is independent of current debt, D, and so is the solution to the equation. Therefore, if the collateral constraint is binding in a open neighborhood around $D$, we can conclude that $\frac{\partial d^{\prime}(D, s)}{\partial D}=0$.

Suppose now that in state $\mathbf{s}=(D, s)$ the collateral constraint is not binding. Then the Euler equation of the household holds:

$$
u_{\mathrm{T}}\left(d^{\prime}(D, s)+y^{\mathrm{T}}-R D, y^{\mathrm{N}}\right)=\beta R \mathbb{E}\left[u_{\mathrm{T}}\left(c^{\mathrm{T}}\left(d^{\prime}(D, s), s\right), y^{\mathrm{N}^{\prime}}\right)\right] .
$$

Suppose by contradiction that $\frac{\partial d^{\prime}(D, s)}{\partial D}<0$ in an open neighborhood around $D$ and consider a debt level $\tilde{D}>D$ belonging to such neighborhood. Because the Euler equation must hold at $\tilde{D}$, we get

$$
u_{\mathrm{T}}\left(d^{\prime}(\tilde{D}, s)+y^{\mathrm{T}}-R \tilde{D}, y^{\mathrm{N}}\right)=\beta R \mathbb{E}\left[u_{\mathrm{T}}\left(c^{\mathrm{T}}\left(d^{\prime}(\tilde{D}, s), s\right), y^{\mathrm{N}^{\prime}}\right)\right] .
$$

But given that the consumption function is non-increasing in debt, i.e., $\frac{\partial c^{\mathrm{T}}(D, s)}{\partial D} \leq 0$, the following must hold:

$$
\begin{aligned}
u_{\mathrm{T}}\left(d^{\prime}(\tilde{D}, s)+y^{\mathrm{T}}-R \tilde{D}, y^{\mathrm{N}}\right) & >u_{\mathrm{T}}\left(d^{\prime}(D, s)+y^{\mathrm{T}}-R D, y^{\mathrm{N}}\right) \\
= & \beta R \mathbb{E}\left[u_{\mathrm{T}}\left(c^{\mathrm{T}}\left(d^{\prime}(D, s), s\right), y^{\mathrm{N}^{\prime}}\right)\right]>\beta R \mathbb{E}\left[u_{\mathrm{T}}\left(c^{\mathrm{T}}\left(d^{\prime}(\tilde{D}, s), s\right), y^{\mathrm{N}^{\prime}}\right)\right],
\end{aligned}
$$

which contradicts the fact that the Euler equation holds with equality at $\tilde{D}$. 


\section{A.2. Proof of Theorem 1}

In the constrained-efficient allocation, the social planner solves the following optimization problem, taking as given the policies of future planners

$$
W(D, s)=\max _{c^{\mathrm{T}}, c^{\mathrm{N}}, D^{\prime}} u\left(A\left(c^{\mathrm{T}}, c^{\mathrm{N}}\right)\right)+\beta \mathbb{E}\left[W\left(D^{\prime}, s^{\prime}\right)\right]
$$

subject to $\quad c^{\mathrm{T}}=y^{\mathrm{T}}+D^{\prime}-R D, \quad c^{\mathrm{N}}=y^{\mathrm{N}}$

$$
\begin{aligned}
& D^{\prime} \leq \bar{d}\left(\left\{p^{(h)}\left(D^{(h)}, s^{(h)}\right), s^{(h)}\right\}_{h=0}^{H}\right), \\
& p^{(0)}(D, s)=\frac{A_{N}\left(c^{\mathrm{T}}, c^{\mathrm{N}}\right)}{A_{T}\left(c^{\mathrm{T}}, c^{\mathrm{N}}\right)}, \\
& p^{(h)}\left(D^{(h)}, s^{(h)}\right)=\mathcal{P}\left(D^{(h)}, s^{(h)}\right), D^{(h+1)}=\mathcal{D}\left(D^{(h)}, s^{(h)}\right), \Gamma^{(h)}\left(s^{(h)}, s\right), \text { for } 1 \leq h \leq H .
\end{aligned}
$$

The proof consists in showing that the allocations that solve the (SP) problem coincide with those of the decentralized equilibrium, up to a redefinition of the multipliers associated with the collateral constraint. Suppose that the conjectured debt and price functions are the same as in the decentralized equilibrium, i.e.,

$$
\mathcal{D}(D, s)=d^{\prime}(D, s) \quad \text { and } \quad \mathcal{P}(D, s)=p(D, s) .
$$

The first-order conditions of problem (SP) can then be written as follows:

$$
\begin{gathered}
u_{\mathrm{T}}\left(c^{\mathrm{T}}, y^{\mathrm{N}}\right)=\lambda-\frac{\partial \bar{d}\left(\left\{p^{(h)}, s^{(h)}\right\}_{h=0}^{H}\right)}{\partial p^{(0)}} \frac{\partial\left(\frac{A_{N}\left(c^{\mathrm{T}}, c^{\mathrm{N}}\right)}{A_{T}\left(c^{\mathrm{T}}, c^{\mathrm{N}}\right)}\right)}{\partial c^{\mathrm{T}}} \mu^{S P}, \\
\lambda=-\beta \mathbb{E} \frac{\partial W\left(D^{\prime}, s^{\prime}\right)}{\partial D^{\prime}}+\mu^{S P}\left(1-\frac{\partial \bar{d}\left(\left\{p^{(h)}, s^{(h)}\right\}_{h=0}^{H}\right)}{\partial p^{(1)}} \frac{\partial p\left(D^{\prime}, s\right)}{\partial D^{\prime}}\right. \\
\left.-\sum_{h=2}^{H} \frac{\partial \bar{d}\left(\left\{p^{(h)}, s^{(h)}\right\}_{h=0}^{H}\right)}{\partial p^{(h)}} \frac{\partial p\left(D^{(h)}, s\right)}{\partial D^{(h)}} \prod_{j=1}^{h-1} \frac{\partial d^{\prime}\left(D^{(j)}, s\right)}{\partial D^{(j)}}\right),
\end{gathered}
$$

together with the complementary slackness and nonnegativity conditions

$$
\mu^{S P}\left[D^{\prime}-\bar{d}\left(\left\{p^{(h)}\left(D^{(h)}, s^{(h)}\right), s^{(h)}\right\}_{h=0}^{H}\right)\right]=0, \quad \mu^{S P} \geq 0 .
$$

Using the assumption that $\frac{\partial \bar{d}\left(\left\{p^{(h)}, s^{(h)}\right\}_{h=0}^{H}\right)}{\partial p^{(0)}}=0$, equation (16) simply reduces to

$$
u_{\mathrm{T}}\left(c^{\mathrm{T}}, y^{\mathrm{N}}\right)=\lambda
$$

Combining this expression with (17) and with the envelope condition, $\frac{\partial W\left(D^{\prime}, s^{\prime}\right)}{\partial D^{\prime}}=-R \lambda^{\prime}$, we obtain 
the Euler equation of the social planner:

$$
\begin{aligned}
u_{\mathrm{T}}\left(c^{\mathrm{T}}, y^{\mathrm{N}}\right)=\beta R \mathbb{E}\left[u_{\mathrm{T}}\left(c^{\mathrm{T}^{\prime}}, y^{\mathrm{N}^{\prime}}\right)\right] & +\mu\left(1-\frac{\partial \bar{d}\left(\left\{p^{(h)}, s^{(h)}\right\}_{h=0}^{H}\right)}{\partial p^{(1)}} \frac{\partial p\left(D^{\prime}, s\right)}{\partial D^{\prime}}\right. \\
& \left.-\sum_{h=2}^{H} \frac{\partial \bar{d}\left(\left\{p^{(h)}, s^{(h)}\right\}_{h=0}^{H}\right)}{\partial p^{(h)}} \frac{\partial p\left(D^{(h)}, s\right)}{\partial D^{(h)}} \prod_{j=1}^{h-1} \frac{\partial d^{\prime}\left(D^{(j)}, s\right)}{\partial D^{(j)}}\right) .
\end{aligned}
$$

Conjecture the following expression for the planner's multiplier on the borrowing constraint:

$\mu^{\mathrm{SP}}=\left(1-\frac{\partial \bar{d}\left(\left\{p^{(h)}, s^{(h)}\right\}_{h=0}^{H}\right)}{\partial p^{(1)}} \frac{\partial p\left(D^{\prime}, s\right)}{\partial D^{\prime}}-\sum_{h=2}^{H} \frac{\partial \bar{d}\left(\left\{p^{(h)}, s^{(h)}\right\}_{h=0}^{H}\right)}{\partial p^{(h)}} \frac{\partial p\left(D^{(h)}, s\right)}{\partial D^{(h)}} \prod_{j=1}^{h-1} \frac{\partial d^{\prime}\left(D^{(j)}, s\right)}{\partial D^{(j)}}\right)^{-1} \mu$,

where $\mu$ is the multipler on the collateral constraint in the competitive equilibrium.

This mapping guarantees that the Euler equation of the social planner is the same as the Euler equation of the competitive equilibrium. We then need to show that the multiplier defined above satisfies the other optimality conditions - namely, the complementary slackness and nonnegativity conditions. The former is clearly satisfied, since the multiplier, $\mu^{\mathrm{SP}}$, is just a rescaling of the competitive equilibrium multiplier. Hence, it is left to show that $\mu^{\mathrm{SP}} \geq 0$.

Our assumptions on preferences and consumption-aggregation technology imply that the relative price is an increasing function of tradable consumption. Hence, using the assumption that the tradable consumption function is non-increasing in debt, we obtain

$$
\frac{\partial p\left(D^{(h)}, s\right)}{\partial D^{(h)}} \leq 0
$$

By Lemma 1 we also have that

$$
\frac{\partial d^{\prime}\left(D^{(h)}, s\right)}{\partial D^{(h)}} \geq 0
$$

The result then follows from the assumption that the borrowing limit is non-decreasing in prices, i.e.,

$$
\frac{\partial \bar{d}\left(\left\{p^{(h)}, s^{(h)}\right\}_{h=0}^{H}\right)}{\partial p^{(h)}} \geq 0
$$

\section{A.3. Generalization to Multiple Constraints}

Theorem 1 assumes that the debt limit is a differentiable function of current and future prices. This assumption is violated in the case of the future-income constraint defined in (4). However, we show in the following lemma that such constraint can be equivalently expressed as $K$ differentiable constraints. 
Lemma 2. A debt level d satisfies

$$
d \leq \min _{\substack{\left\{y_{t+1}^{T}\left(s^{t+1}\right), y_{t+1}^{N}\left(s^{t+1}\right) \\ p_{t+1}\left(s^{t+1}\right)\right\} \mid s^{t}}} \kappa\left(s^{t}\right)\left(y_{t+1}^{T}\left(s^{t+1}\right)+p_{t+1}\left(s^{t+1}\right) y_{t+1}^{N}\left(s^{t+1}\right)\right)
$$

if and only if it satisfies

$$
d \leq \mathcal{D}_{k}\left(\left\{\mathcal{P}\left(c_{t+h}^{T}\left(s^{t+h}\right), y_{t+h}^{N}\left(s^{t+h}\right)\right), s^{t+h}\right\}_{h=0, s^{t+h} \in S^{t+h}}^{H}\right) \forall k=1, \ldots, K
$$

with $K=|S|$, and

$$
D_{k}\left(\left\{p\left(s^{t+h}\right), s^{t+h}\right\}_{h=0, s^{t+h} \in S^{t+h}}^{H}\right):=\kappa\left(s^{t}\right)\left(y_{t+1}^{T}\left(s_{k} ; s^{t}\right)+p_{t+1}\left(s_{k} ; s^{t}\right) y_{t+1}^{N}\left(s_{k} ; s^{t}\right)\right) .
$$

Proof. The result follows immediately given $|S|<\infty$.

We show next that Theorem 1 generalizes to the case with $\mathrm{K}$ differentiable constraints.

Theorem 4. Consider a solution of the planner problem in which the consumption function $c(D, s)$ is differentiable and non-increasing in debt $D$. If for all $k=1 \ldots, K \bar{d}_{k}\left(\left\{p^{(h)}, s^{(h)}\right\}_{h=0}^{H}\right)$ is differentiable and non-decreasing in $p^{(h)}$ for all $s^{(h)}$ and $\frac{\partial \bar{d}_{k}\left(\left\{p^{(h)}, s^{(h)}\right\}_{h=0}^{H}\right)}{\partial p^{(0)}}=0$, the decentralized equilibrium is constrained efficient, i.e., $\mathbf{x}(D, D, s)=\mathbf{x}^{S P}(D, s)$.

Proof of Theorem 4. The problem of the planner in the general case with multiple constraints is as follows:

$$
W(D, s)=\max _{c^{\mathrm{T}}, c^{\mathrm{N}}, D^{\prime}} u\left(A\left(c^{\mathrm{T}}, c^{\mathrm{N}}\right)\right)+\beta \mathbb{E}\left[W\left(D^{\prime}, s^{\prime}\right)\right]
$$

subject to $\quad c^{\mathrm{T}}=y^{\mathrm{T}}+D^{\prime}-R D$,

$$
\begin{aligned}
& D^{\prime} \leq \bar{d}_{k}\left(\left\{p_{h}\left(D^{(h)}, s^{(h)}\right), s^{(h)}\right\}_{h=0}^{H}\right), \\
& p_{0}(D, s)=\frac{A_{N}\left(c^{\mathrm{T}}, c^{\mathrm{N}}\right)}{A_{T}\left(c^{\mathrm{T}}, c^{\mathrm{N}}\right)}, \\
& p_{h}\left(D^{(h)}, s^{(h)}\right)=\mathcal{P}\left(D^{(h)}, s^{(h)}\right), D^{(h+1)}=\mathcal{D}\left(D^{(h)}, s^{(h)}\right), \Gamma^{(h)}\left(s^{(h)}, s\right), \text { for } 1 \leq h \leq H .
\end{aligned}
$$

Taking the first-order conditions of the planner's problem and using the fact that for all $k=1 \ldots, K$ $\frac{\partial \bar{d}_{k}\left(\left\{p^{(h)}, s^{(h)}\right\}_{h=0}^{H}\right)}{\partial p^{(0)}}=0$, we obtain the following conditions:

$$
\begin{gathered}
u_{\mathrm{T}}\left(c^{\mathrm{T}}, y^{\mathrm{N}}\right)=\lambda, \\
\lambda=-\beta \mathbb{E}\left[\frac{\partial W\left(D^{\prime}, s^{\prime}\right)}{\partial D^{\prime}}\right]+\sum_{k=1}^{K} \mu_{k}^{S P}\left(1-\frac{\partial \bar{d}_{k}\left(\left\{p^{(h)}, s^{(h)}\right\}_{h=0}^{H}\right)}{\partial p^{(1)}} \frac{\partial p\left(D^{\prime}, s\right)}{\partial D^{\prime}}\right. \\
\left.-\sum_{h=2}^{H} \frac{\partial \bar{d}_{k}\left(\left\{p^{(h)}, s^{(h)}\right\}_{h=0}^{H}\right)}{\partial p^{(h)}} \frac{\partial p\left(D^{(h)}, s\right)}{\partial D^{(h)}} \prod_{j=1}^{h-1} \frac{\partial d^{\prime}\left(D^{(j)}, s\right)}{\partial D^{(j)}}\right) .
\end{gathered}
$$

Combining the above expressions with the envelope condition, $\frac{\partial W\left(D^{\prime}, s^{\prime}\right)}{\partial D^{\prime}}=-R \lambda^{\prime}$, yields the plan- 
ner's Euler equation:

$$
\begin{aligned}
u_{\mathrm{T}}\left(c^{\mathrm{T}}, y^{\mathrm{N}}\right)=\beta R \mathbb{E}\left[u_{\mathrm{T}}\left(c^{\mathrm{T}^{\prime}}, y^{\mathrm{N}^{\prime}}\right)\right]+ & \sum_{k=1}^{K} \mu_{k}^{S P}\left(1-\frac{\partial \bar{d}_{k}\left(\left\{p^{(h)}, s^{(h)}\right\}_{h=0}^{H}\right)}{\partial p^{(1)}} \frac{\partial p\left(D^{\prime}, s\right)}{\partial D^{\prime}}\right. \\
& \left.-\sum_{h=2}^{H} \frac{\partial \bar{d}_{k}\left(\left\{p^{(h)}, s^{(h)}\right\}_{h=0}^{H}\right)}{\partial p^{(h)}} \frac{\partial p\left(D^{(h)}, s\right)}{\partial D^{(h)}} \prod_{j=1}^{h-1} \frac{\partial d^{\prime}\left(D^{(j)}, s\right)}{\partial D^{(j)}}\right) .
\end{aligned}
$$

Conjecture the following mapping between the multipliers of the social planner and those of the competitive equilibrium

$$
\begin{aligned}
\mu_{k}^{\mathrm{SP}}=(1- & \frac{\partial \bar{d}_{k}\left(\left\{p^{(h)}, s^{(h)}\right\}_{h=0}^{H}\right)}{\partial p^{(1)}} \frac{\partial p\left(D^{\prime}, s\right)}{\partial D^{\prime}} \\
& \left.\quad-\sum_{h=2}^{H} \frac{\partial \bar{d}_{k}\left(\left\{p^{(h)}, s^{(h)}\right\}_{h=0}^{H}\right)}{\partial p^{(h)}} \frac{\partial p\left(D^{(h)}, s\right)}{\partial D^{(h)}} \prod_{j=1}^{h-1} \frac{\partial d^{\prime}\left(D^{(j)}, s\right)}{\partial D^{(j)}}\right)^{-1} \mu, \quad \text { for all } k=1, \ldots, K .
\end{aligned}
$$

The result then follows from the observation that

$$
\begin{gathered}
\frac{\partial p\left(D^{(h)}, s\right)}{\partial D^{(h)}} \leq 0, \\
\frac{\partial d^{\prime}\left(D^{(h)}, s\right)}{\partial D^{(h)}} \geq 0,
\end{gathered}
$$

and

$$
\frac{\partial \bar{d}_{k}\left(\left\{p^{(h)}, s^{(h)}\right\}_{h=0}^{H}\right)}{\partial p^{(h)}} \geq 0, \quad \text { for all } k=1, \ldots, K .
$$

\section{A.4. Optimal Policy under Commitment}

Proof of Theorem 2. Consider the social planner's problem under commitment. Imposing the assumption that $H=1$ and $\frac{\partial \bar{d}\left(\left\{p^{(h)}, s^{(h)}\right\}_{h=0}^{H}\right)}{\partial p^{(0)}}=0$, we can write the planner's problem as follows:

$$
\begin{array}{cl} 
& \max _{\left\{c_{t}^{T}\left(s^{t}\right), D_{t+1}\left(s^{t}\right)\right\}} \mathbb{E}_{0} \sum_{t=0}^{\infty} \beta^{t} u\left(A\left(c_{t}^{T}\left(s^{t}\right), y_{t}^{N}\left(s^{t}\right)\right)\right) \\
\text { subject to } \quad & c_{t}^{T}\left(s^{t}\right)=y_{t}^{T}\left(s^{t}\right)+D_{t+1}\left(s^{t}\right)-R D_{t}\left(s^{t}\right), \\
& D_{t+1}\left(s^{t}\right) \leq \bar{d}\left(s^{t},\left\{p\left(c_{t+1}^{T}\left(s^{t+1}\right), y_{t+1}^{N}\left(s^{t+1}\right)\right), s^{t+1}\right\}\right), \\
& p\left(c_{t}^{T}\left(s^{t}\right), y_{t}^{N}\left(s^{t}\right)\right)=\frac{A_{N}\left(c_{t}^{\mathrm{T}}\left(s^{t}\right), y_{t}^{\mathrm{N}}\left(s^{t}\right)\right)}{A_{T}\left(c_{t}^{\mathrm{T}}\left(s^{t}\right), y_{t}^{\mathrm{N}}\left(s^{t}\right)\right)},
\end{array}
$$


for a given $d_{0}\left(s^{-1}\right)$.

For the sake of exposition, we keep the state notation implict and use $\bar{d}_{t}$ to denote the borrowing limit at time $t$. The first-order conditions of the planner's problem are given by

$$
\begin{gathered}
u_{\mathrm{T}}\left(c_{0}^{T}, y_{0}^{N}\right)=\lambda_{0}, \\
\beta^{t} u_{\mathrm{T}}\left(c_{t}^{T}, y_{t}^{N}\right)=\lambda_{t}-\mu_{t-1}^{S P} \frac{\partial \bar{d}_{t-1}\left(p\left(c_{t}^{T}, y_{t}^{N}\right)\right)}{\partial p\left(c_{t}^{T}, y_{t}^{N}\right)} \frac{\partial p\left(c_{t}^{T}, y_{t}^{N}\right)}{\partial c_{t}^{T}} \text { for } t>0, \\
\lambda_{t}=R \mathbb{E}_{t} \lambda_{t+1}+\mu_{t} .
\end{gathered}
$$

Combining these expressions, we derive the Euler equation of the social planner:

$$
\begin{aligned}
u_{\mathrm{T}}\left(c_{t}^{T}, y_{t}^{N}\right)=\beta R \mathbb{E}_{t} u_{\mathrm{T}}\left(c_{t+1}^{T}, y_{t+1}^{N}\right)- & \mu_{t-1}^{S P} \frac{\partial \bar{d}_{t-1}\left(p\left(c_{t}^{T}, y_{t}^{N}\right)\right)}{\partial p\left(c_{t}^{T}, y_{t}^{N}\right)} \frac{\partial p\left(c_{t}^{T}, y_{t}^{N}\right)}{\partial c_{t}^{T}} \\
& +\mu_{t}^{S P}\left(1+\beta R \mathbb{E}_{t} \frac{\partial \bar{d}_{t}\left(p\left(c_{t+1}^{T}, y_{t+1}^{N}\right)\right)}{\partial p\left(c_{t+1}^{T}, y_{t+1}^{N}\right)} \frac{\partial p\left(c_{t+1}^{T}, y_{t+1}^{N}\right)}{\partial c_{t+1}^{T}}\right)
\end{aligned}
$$

Let $\tau_{t}$ denote the tax, if positive, or the subsidy, if negative, levied on debt issued at time $t$. Then the Euler equation in the decentralized equilibrium is given by

$$
u_{\mathrm{T}}\left(c_{t}^{T}, y_{t}^{N}\right)=\beta R\left(1+\tau_{t}\right) \mathbb{E}_{t} u_{\mathrm{T}}\left(c_{t+1}^{T}, y_{t+1}^{N}\right)+\mu_{t} .
$$

This equation implies the following expression for the tax/subsidy that implements the optimal allocation:

$$
\tau_{t}=\frac{u_{\mathrm{T}}\left(c_{t}^{T}, y_{t}^{N}\right)-\beta R \mathbb{E}_{t} u_{\mathrm{T}}\left(c_{t+1}^{T}, y_{t+1}^{N}\right)}{\beta R \mathbb{E}_{t} u_{\mathrm{T}}\left(c_{t+1}^{T}, y_{t+1}^{N}\right)}
$$

Suppose, first, that the constraint is not binding at time $t$. Then the term on the second line of (24) is equal to zero. Hence, we have that

$$
u_{\mathrm{T}}\left(c_{t}^{T}, y_{t}^{N}\right)-\beta R \mathbb{E}_{t} u_{\mathrm{T}}\left(c_{t+1}^{T}, y_{t+1}^{N}\right)=-\mu_{t-1}^{S P} \frac{\partial \bar{d}_{t-1}\left(p\left(c_{t}^{T}, y_{t}^{N}\right)\right)}{\partial p\left(c_{t}^{T}, y_{t}^{N}\right)} \frac{\partial p\left(c_{t}^{T}, y_{t}^{N}\right)}{\partial c_{t}^{T}} \leq 0
$$

This in turn implies

$$
\tau_{t}=-\frac{\mu_{t-1}^{S P} \frac{\partial \bar{d}\left(p\left(c_{t}^{T}, y_{t}^{N}\right)\right)}{\partial p\left(c_{t}^{T}, y_{t}^{N}\right)} \frac{\partial p\left(c_{t}^{T}, y_{t}^{N}\right)}{\partial c_{t}^{T}}}{\beta R \mathbb{E}_{t} u_{\mathrm{T}}\left(c_{t+1}^{T}, y_{t+1}^{N}\right)} \leq 0
$$

with strict inequality if $\mu_{t-1}>0, \frac{\partial \bar{d}\left(s^{t-1},\left\{p\left(c_{t}^{T}, y_{t}^{N}\right), s^{t}\right\}\right)}{\partial p\left(c_{t}^{T}, y_{t}^{N}\right)}>0$ and $\frac{\partial p\left(c_{t}^{T}, y_{t}^{N}\right)}{\partial c_{t}^{T}}>0$. Suppose now that the 
constraint is binding at time $t$ for the social planner. Consider, first, the case, in which

$$
-\mu_{t-1}^{S P} \frac{\partial \bar{d}\left(p\left(c_{t}^{T}, y_{t}^{N}\right)\right)}{\partial p\left(c_{t}^{T}, y_{t}^{N}\right)} \frac{\partial p\left(c_{t}^{T}, y_{t}^{N}\right)}{\partial c_{t}^{T}}+\mu_{t}^{S P}\left(1+\beta R \mathbb{E}_{t} \frac{\partial \bar{d}\left(p\left(c_{t+1}^{T}, y_{t+1}^{N}\right)\right)}{\partial p\left(c_{t+1}^{T}, y_{t+1}^{N}\right)} \frac{\partial p\left(c_{t+1}^{T}, y_{t+1}^{N}\right)}{\partial c_{t+1}^{T}}\right)<0
$$

which implies that

$$
u_{\mathrm{T}}\left(c_{t}^{T}, y_{t}^{N}\right)-\beta R \mathbb{E}_{t} u_{\mathrm{T}}\left(c_{t+1}^{T}, y_{t+1}^{N}\right)<0 .
$$

Suppose by contradiction that $\tau_{t} \geq 0$. Then the Euler equation of the decentralized equilibrium implies that

$$
\mu_{t}=u_{\mathrm{T}}\left(c_{t}^{T}, y_{t}^{N}\right)-\beta R\left(1+\tau_{t}\right) \mathbb{E}_{t} u_{\mathrm{T}}\left(c_{t+1}^{T}, y_{t+1}^{N}\right) \leq u_{\mathrm{T}}\left(c_{t}^{T}, y_{t}^{N}\right)-\beta R \mathbb{E}_{t} u_{\mathrm{T}}\left(c_{t+1}^{T}, y_{t+1}^{N}\right)<0 .
$$

This contradicts the fact that in the decentralized equilibrium the multiplier is nonnegative. As a result, we have that $\tau_{t}<0$, with the expression for the optimal subsidy given by

$$
\tau_{t}=\frac{-\mu_{t-1}^{S P} \frac{\partial \bar{d}\left(p\left(c_{t}^{T}, y_{t}^{N}\right)\right)}{\partial p\left(c_{t}^{T}, y_{t}^{N}\right)} \frac{\partial p\left(c_{t}^{T}, y_{t}^{N}\right)}{\partial c_{t}^{T}}+\mu_{t}^{S P}\left(1+\beta R \mathbb{E}_{t} \frac{\partial \bar{d}\left(p\left(c_{t+1}^{T}, y_{t+1}^{N}\right)\right)}{\partial p\left(c_{t+1}^{T}, y_{t+1}^{N}\right)} \frac{\partial p\left(c_{t+1}^{T}, y_{t+1}^{N}\right)}{\partial c_{t+1}^{T}}\right)}{\beta R \mathbb{E}_{t} u_{\mathrm{T}}\left(c_{t+1}^{T}, y_{t+1}^{N}\right)}<0 .
$$

Consider now the opposite case, in which

$$
-\mu_{t-1}^{S P} \frac{\partial \bar{d}\left(p\left(c_{t}^{T}, y_{t}^{N}\right)\right)}{\partial p\left(c_{t}^{T}, y_{t}^{N}\right)} \frac{\partial p\left(c_{t}^{T}, y_{t}^{N}\right)}{\partial c_{t}^{T}}+\mu_{t}^{S P}\left(1+\beta R \mathbb{E}_{t} \frac{\partial \bar{d}\left(p\left(c_{t+1}^{T}, y_{t+1}^{N}\right)\right)}{\partial p\left(c_{t+1}^{T}, y_{t+1}^{N}\right)} \frac{\partial p\left(c_{t+1}^{T}, y_{t+1}^{N}\right)}{\partial c_{t+1}^{T}}\right) \geq 0 .
$$

Then

$$
u_{\mathrm{T}}\left(c_{t}^{T}, y_{t}^{N}\right)-\beta R \mathbb{E}_{t} u_{\mathrm{T}}\left(c_{t+1}^{T}, y_{t+1}^{N}\right)>0 .
$$

By setting $\tau_{t}=0$, we have the following Euler equation:

$$
\mu_{t}=u_{\mathrm{T}}\left(c_{t}^{T}, y_{t}^{N}\right)-\beta R \mathbb{E}_{t} u_{\mathrm{T}}\left(c_{t+1}^{T}, y_{t+1}^{N}\right)>0 .
$$

Since $\mu>0$, both the planner and the private agent borrow up to the limit. Hence, setting $\tau_{t}=0$ implements the optimal policy. 


\section{A.5. Model with Capital}

Proof of Theorem 3. In the constrained-efficient allocation the social planner solves the following optimization problem, taking as given the policies of future planners:

$$
\begin{array}{ll} 
& W(D, s)=\max _{c, D^{\prime}, q, \mu} u(c)+\beta \mathbb{E}\left[W\left(D^{\prime}, s^{\prime}\right)\right] \\
\text { subject to } \quad & c+R D=z+D^{\prime}, \\
& D^{\prime} \leq \kappa \min _{s^{\prime}}\left\{\mathcal{Q}\left(D^{\prime}, s^{\prime}\right)\right\}, \\
& q u^{\prime}(c)=\beta \mathbb{E}\left[\left(\alpha z^{\prime}+\mathcal{Q}\left(D^{\prime}, s^{\prime}\right)\right) u^{\prime}\left(\mathcal{C}\left(D^{\prime}, s^{\prime}\right)\right)\right]+\mu \kappa \min _{s^{\prime}}\left\{\mathcal{Q}\left(D^{\prime}, s^{\prime}\right)\right\}, \\
& \mu\left[D^{\prime}-\kappa \min _{s^{\prime}}\left\{\mathcal{Q}\left(D^{\prime}, s^{\prime}\right)\right\}\right]=0, \quad \mu \geq 0 .
\end{array}
$$

Given the optimal choice for consumption and debt, the third and fourth constraints pin down residually the asset price and competitive equilibrium multiplier. Therefore, we can solve for the consumption and debt policies by solving the following reduced problem:

$$
\begin{array}{ll} 
& W(D, s)=\max _{c, D^{\prime}} u(c)+\beta \mathbb{E}\left[W\left(D^{\prime}, s^{\prime}\right)\right] \\
\text { subject to } & c+R D=z+D^{\prime}, \\
& D^{\prime} \leq \kappa \min _{s^{\prime}}\left\{\mathcal{Q}\left(D^{\prime}, s^{\prime}\right)\right\} .
\end{array}
$$

Now, set $\mathcal{Q}(D, s)=q(D, s)$, where $q(D, s)$ is the competitive equilibrium price function. Taking first-order conditions for the above maximization problem yields the following Euler equation for the social planner:

$$
u^{\prime}(c)=\beta R \mathbb{E} u^{\prime}\left(c^{\prime}\right)+\mu^{\mathrm{SP}}\left[1-\kappa \frac{\partial \min _{s^{\prime}}\left\{q\left(D^{\prime}, s^{\prime}\right)\right\}}{\partial D^{\prime}}\right] .
$$

Comparing this expression with the Euler equation of the competitive equilibrium allows us to derive the following relationship between the multiplier of the social planner and that of the household:

$$
\mu^{\mathrm{SP}}=\left[1-\kappa \frac{\partial \min _{s^{\prime}}\left\{q\left(D^{\prime}, s^{\prime}\right)\right\}}{\partial D^{\prime}}\right]^{-1} \mu .
$$

The competitive equilibrium policies and the multiplier $\mu^{\mathrm{SP}}$ jointly satisfy the planner's Euler equation and the complementary slackness condition. In addition, the assumption that $\left(1-\kappa \frac{\partial \min _{s} q(D, s)}{\partial D}\right)>$ 0 ensures that the multiplier $\mu^{\mathrm{SP}}$ is nonnegative. It follows that the competitive equilibrium allocation solves the planner's optimality conditions, proving the result. 


\section{B. Quantitative Analysis}

\section{B.1. Equilibrium Policies}

Figure B.1: Bond Policy Functions - Current Income

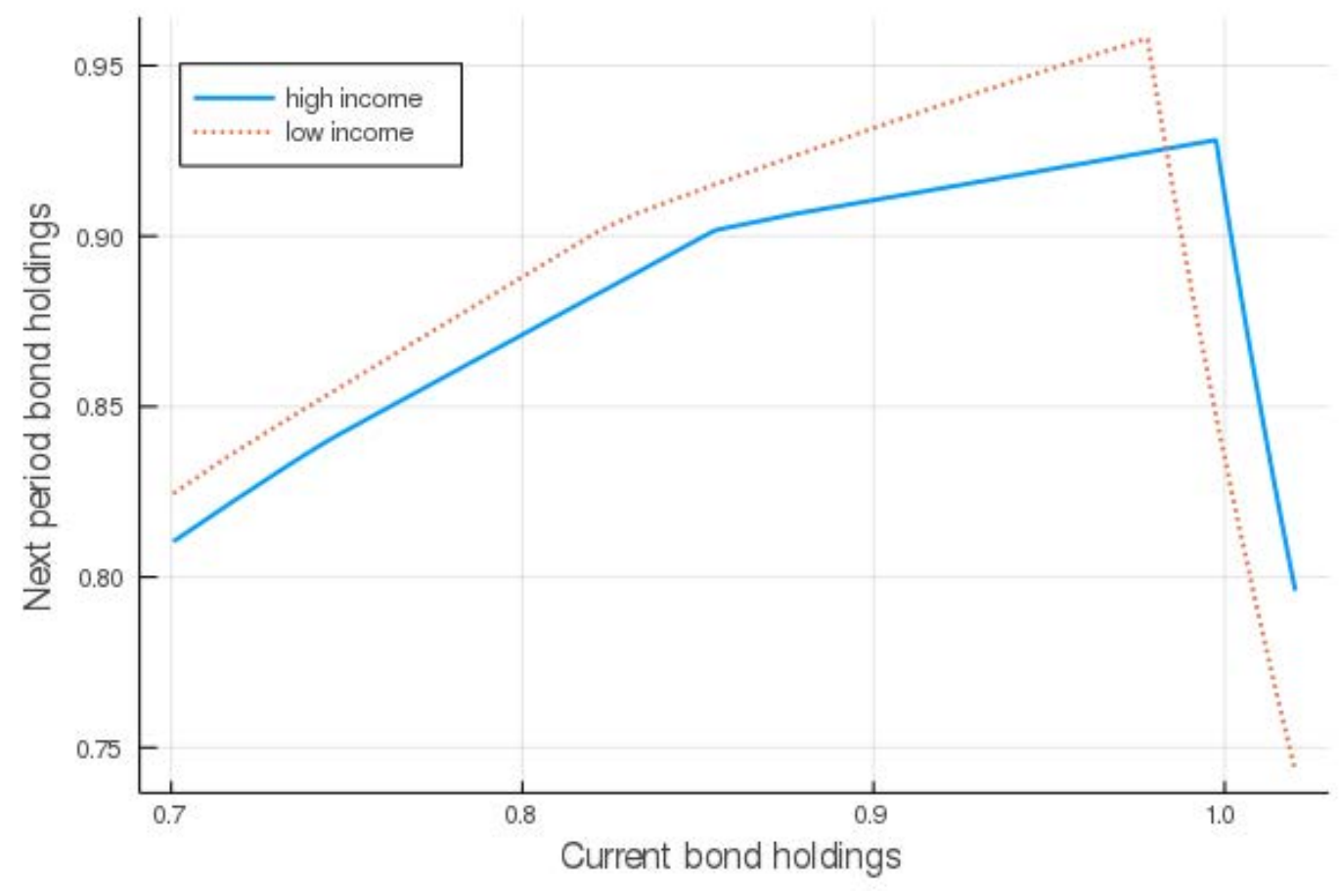

Notes: This figure plots the bond policy function at different income levels for the current-income-constraint economy. 
Figure B.2: Bond Policy Functions - Social Planner vs. Decentralized Equilibrium

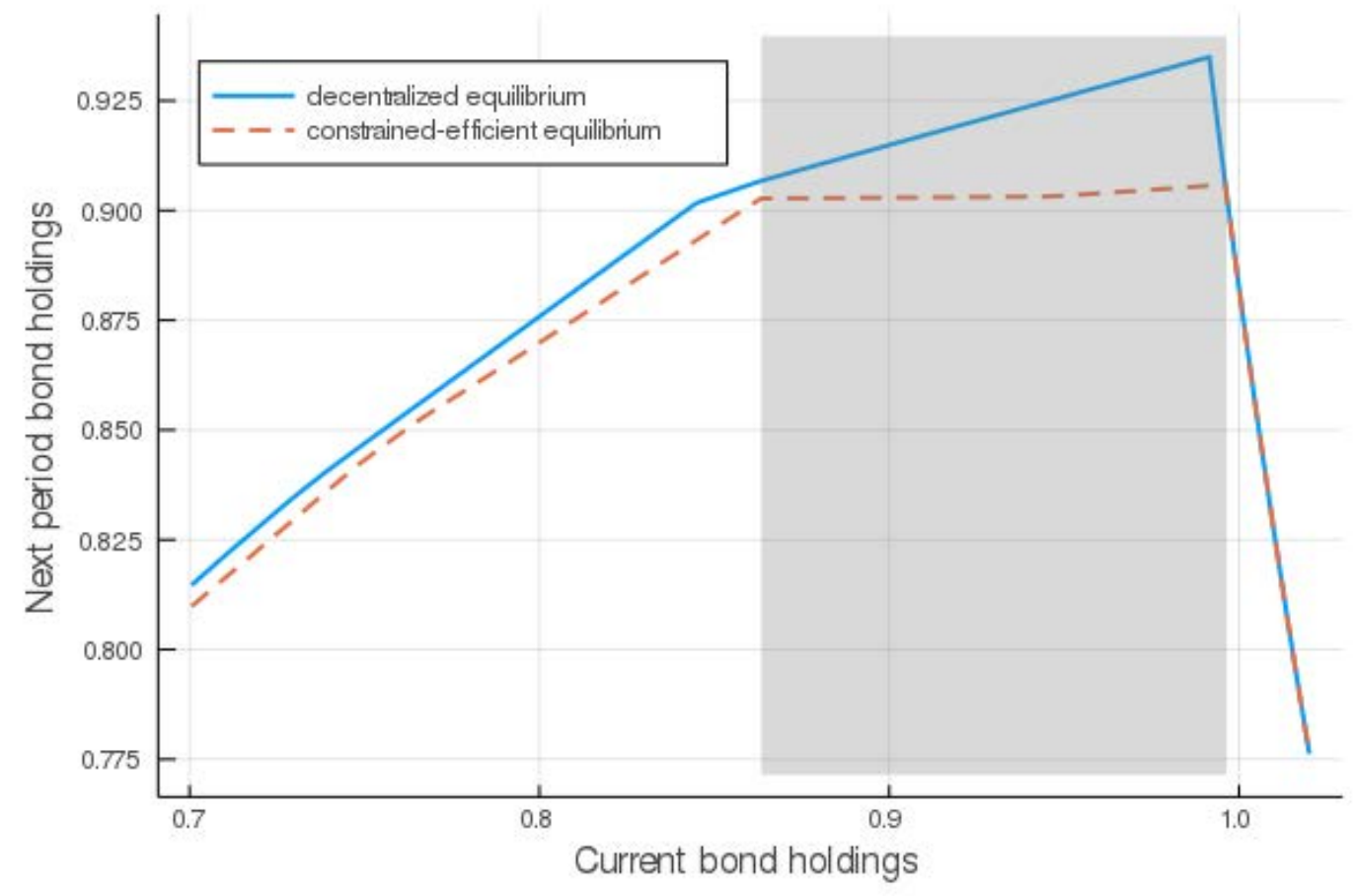

Notes: This figure plots the bond policy functions in the constrained-efficient equilibrium and in the decentralized equilibrium for the current-income-constraint economy. The shaded area corresponds to levels of current bond holdings at which the optimal capital taxes are strictly positive. 
Figure B.3: Bond Policy Functions - Future Income

(a) Normal Credit Regime

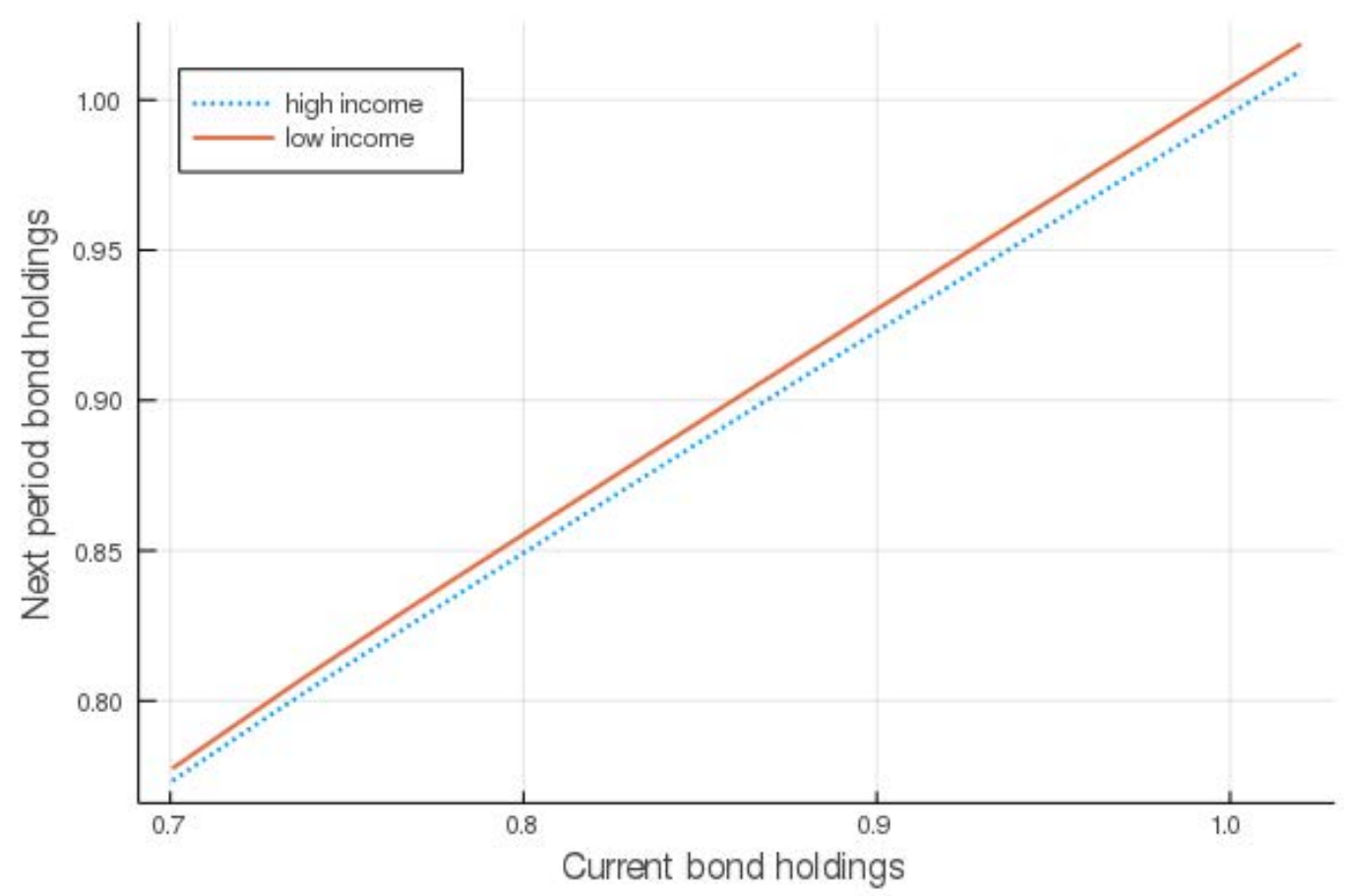

(b) Tight Credit Regime

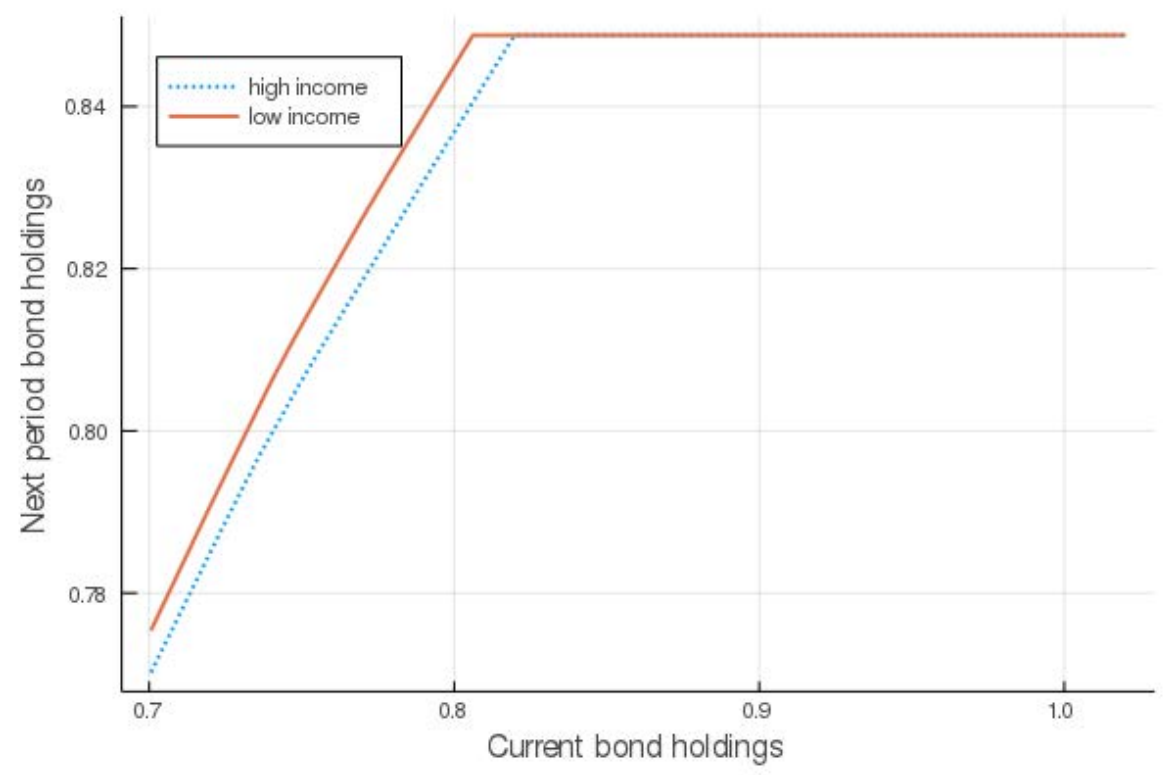

Notes: This figure plots the bond policy functions at different income levels for the future-income-constraint economy. Panels (A) and (B) refer, respectively, to the normal and tight credit regimes. 
Figure B.4: Bond Policy Functions - Social Planner vs. Inefficient Taxes

(a) Normal Credit Regime

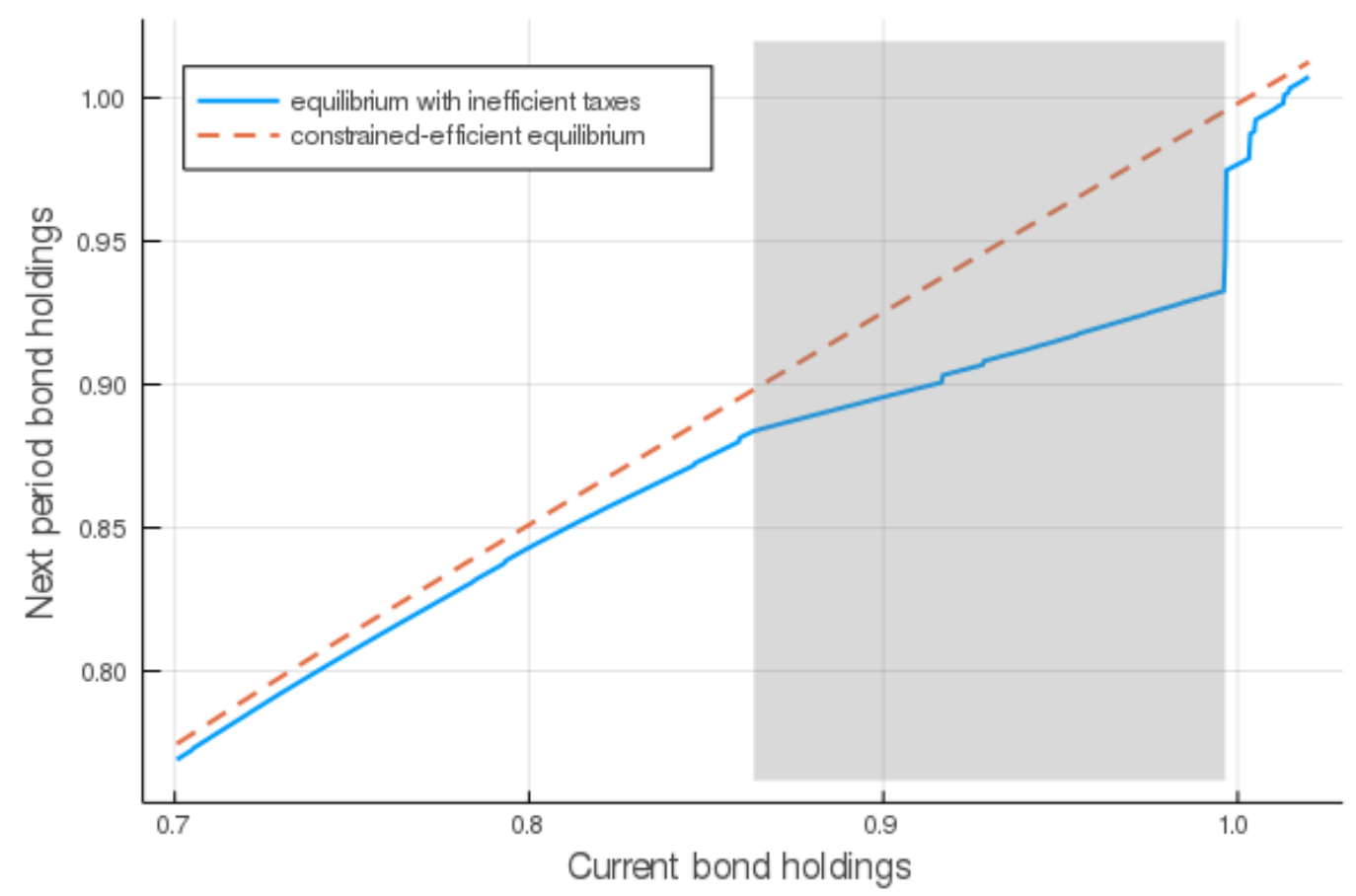

(b) Tight Credit Regime

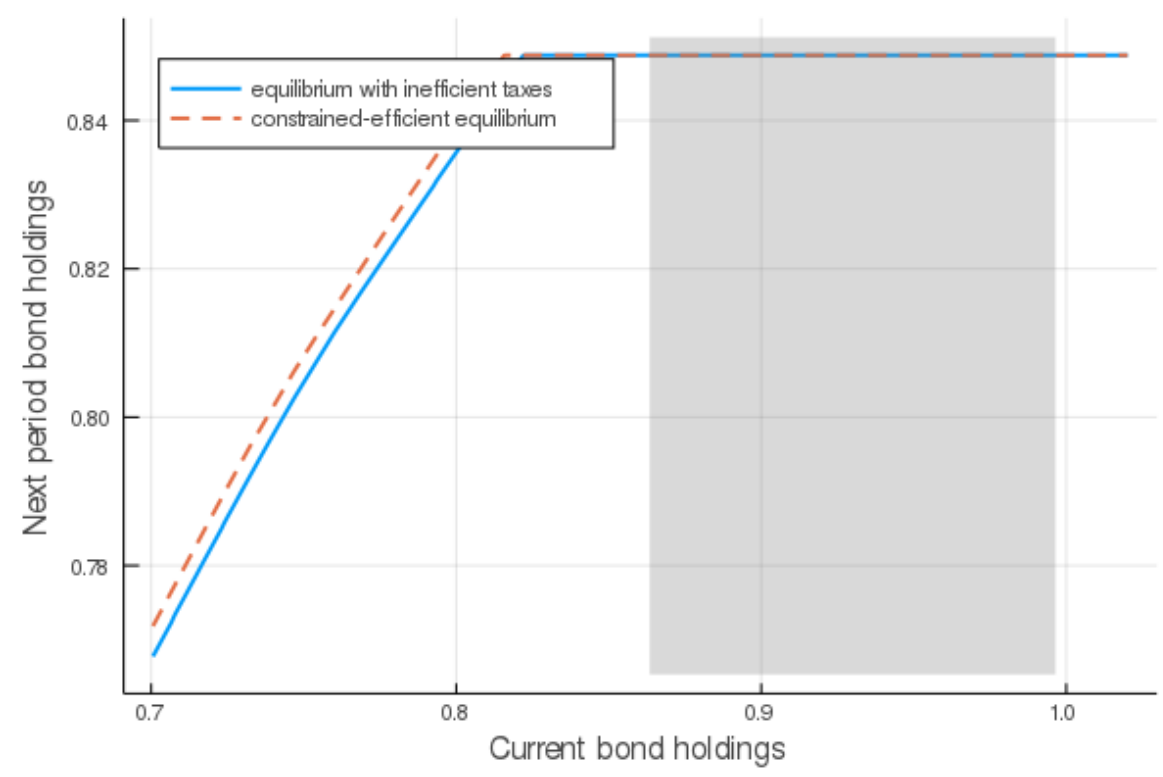

Notes: This figure plots the bond policy functions for the future-income-constraint economy. It compares the policy function in the constrained-efficient equilibrium with the policy function of the decentralized equilibrium under model misspecification. The shaded area corresponds to levels of current bond holdings at which the optimal capital taxes under model misspecification are strictly positive. Panels (A) and (B) refer, respectively, to the normal and tight credit regimes. 


\section{B.2. Future Income Model with No Shocks to Collateral}

We report here the results for the future-income-constraint model without shocks to $\kappa$. Table B.1 reports the values of calibrated parameters for this model. Table B.2 shows the corresponding targeted moments. Finally, B.3 shows second moments regarding business cycles.

Inspecting Table B.3, we notice that the model without shocks to $\kappa$ cannot explain key features of the data; in particular, the model features a strongly procyclical current account and never exhibits sudden stops.

Table B.1: Calibrated Parameters - Future Income without Shocks to $\kappa$

\begin{tabular}{lcc}
\hline \hline & & $\begin{array}{c}\text { Future Income } \\
\text { without Shocks to } \kappa\end{array}$ \\
\hline Weight on tradables in CES & $\omega$ & 0.31 \\
Subjective discount factor & $\beta$ & 0.96 \\
Credit regime & $\kappa$ & 0.55 \\
\hline \hline
\end{tabular}

Notes: This table shows the subset of parameters calibrated to match targeted moments, as detailed in Table B.2.

Table B.2: Targeted Moments - Future Income without Shocks to $\kappa$

\begin{tabular}{lcc}
\hline \hline & \multicolumn{2}{c}{ Future Income } \\
& Data & without Shocks to $\kappa$ \\
\hline Share of tradable output & $0.32 \%$ & $0.32 \%$ \\
Average NFA-GDP ratio & $-29 \%$ & $-29.77 \%$ \\
Frequency of crisis & $5.5 \%$ & $0 \%$ \\
\hline \hline
\end{tabular}

Notes: This table shows the model counterparts of three targeted moments for the future-income-constraint model without shocks to $\kappa$. 
Table B.3: Second Moments - Future Income without Shocks to $\kappa$

\begin{tabular}{lcc}
\hline \hline & Data & $\begin{array}{c}\text { Future Income } \\
\text { without Shocks to } \kappa\end{array}$ \\
\hline Standard deviations & 6.2 & 3.81 \\
$\quad$ Consumption & 8.2 & 5.8 \\
$\quad$ Real Exchange Rate & 3.6 & 1.66 \\
Current account-GDP & 2.4 & 1.84 \\
Trade balance-GDP & & \\
& & \\
Correlation with GDP in units of tradables & 0.88 & 0.83 \\
Consumption & 0.41 & 0.82 \\
$\quad$ Real Exchange Rate & -0.63 & 0.4 \\
Current account-GDP & -0.84 & -0.004 \\
$\quad$ Trade balance-GDP & $-29 \%$ & $-29.77 \%$ \\
\hline Average NFA-GDP ratio & $5.5 \%$ & $0 \%$ \\
Frequency of a crisis & - & $14.08 \%$ \\
Prob( $\mu>0)$ & \\
\hline \hline
\end{tabular}

Notes: This table shows untargeted second moments regarding business cycles and their counterparts in the future-income-constraint model without shocks to $\kappa$. 


\section{B.3. Welfare Costs of Model Misspecification}

We compute welfare losses from not implementing macroprudential policies in the current-incomeconstraint economy as the proportional decrease in consumption for all possible future histories in the constrained-efficient equilibrium that would make households indifferent between remaining in the constrained-efficient allocation and moving to an equilibrium without government intervention. Because of the homotheticity of the utility function, the welfare loss in state $\left(b, y^{T}, y^{N}\right)$ is given by

$$
\left(1+\gamma\left(b, y^{T}, y^{N}\right)\right)^{1-\sigma} V^{\mathrm{sp}, \mathrm{c}}\left(b, y^{T}, y^{N}\right)=V^{\mathrm{notax}, \mathrm{c}}\left(b, y^{T}, y^{N}\right)
$$

, where $V^{\mathrm{sp}, \mathrm{c}}\left(b, y^{T}, y^{N}\right)$ denotes the value function in the constrained-efficient allocation of the current-income-constraint economy, and $V^{\text {no tax,c }}\left(b, y^{T}, y^{N}\right)$ denotes the value function in that economy without government intervention. The mean, standard deviation, and correlation with GDP of welfare losses are then computed using the ergodic distribution of $\left(b, y^{T}, y^{N}\right)$ in the constrainedefficient allocation.

Similarly, we compute welfare losses from implementing macroprudential policies in the futureincome-constraint economy as the proportional decrease in consumption for all possible future histories in the constrained-efficient equilibrium that would make households indifferent between remaining in the constrained-efficient allocation and moving to an equilibrium with inefficient capital control taxes. The welfare loss in state $\left(b, y^{T}, y^{N}\right)$ is given by

$$
\left(1+\hat{\gamma}\left(b, y^{T}, y^{N}\right)\right)^{1-\sigma} V^{\mathrm{sp}, \mathrm{f}}\left(b, y^{T}, y^{N}\right)=V^{\mathrm{tax}, \mathrm{f}}\left(b, y^{T}, y^{N}\right)
$$

where $V^{\mathrm{sp}, \mathrm{f}}\left(b, y^{T}, y^{N}\right)$ denotes the value function in the constrained-efficient equilibrium of the future-income-constraint economy, and $V^{\operatorname{tax}, \mathrm{f}}\left(b, y^{T}, y^{N}\right)$ denotes the value function in that economy with inefficient capital control taxes. The mean, standard deviation, and correlation with GDP of welfare losses are then computed using the ergodic distribution of $\left(b, y^{T}, y^{N}\right)$ in the constrainedefficient equilibrium. 
Table B.4: Second Moments under Model Misspecification

\begin{tabular}{lccc}
\hline \hline & & Social & Inefficient \\
& Data & Planner & Taxes \\
\hline Standard deviations & & & \\
$\quad$ Consumption & 6.2 & 4.62 & 4.57 \\
$\quad$ Real Exchange Rate & 8.2 & 6.2 & 6.2 \\
Current account-GDP & 3.6 & 1.32 & 0.96 \\
Trade balance-GDP & 2.4 & 1.39 & 1.01 \\
& & & \\
Correlation with GDP in units of tradables & & & \\
$\quad$ Consumption & 0.88 & 0.88 & 0.9 \\
$\quad$ Real Exchange Rate & 0.41 & 0.91 & 0.91 \\
$\quad$ Current account-GDP & -0.63 & -0.17 & -0.06 \\
$\quad$ Trade balance-GDP & -0.84 & -0.28 & -0.22 \\
\hline Average NFA-GDP ratio & $-29 \%$ & $-29.2 \%$ & $-28.2 \%$ \\
Frequency of a crisis & $5.5 \%$ & $5.65 \%$ & $5.04 \%$ \\
Prob $(\mu>0)$ & - & $12.71 \%$ & $11.76 \%$ \\
\hline \hline
\end{tabular}

Notes: This table shows untargeted second moments regarding business cycles and their model counterparts in the future-income-constraint economy. It compares the values in the constrained-efficient equilibrium with those in the equilibrium with inefficient capital control taxes. 
Figure B.5: Welfare Losses - Current Income

(a) Welfare Losses Conditional on Income

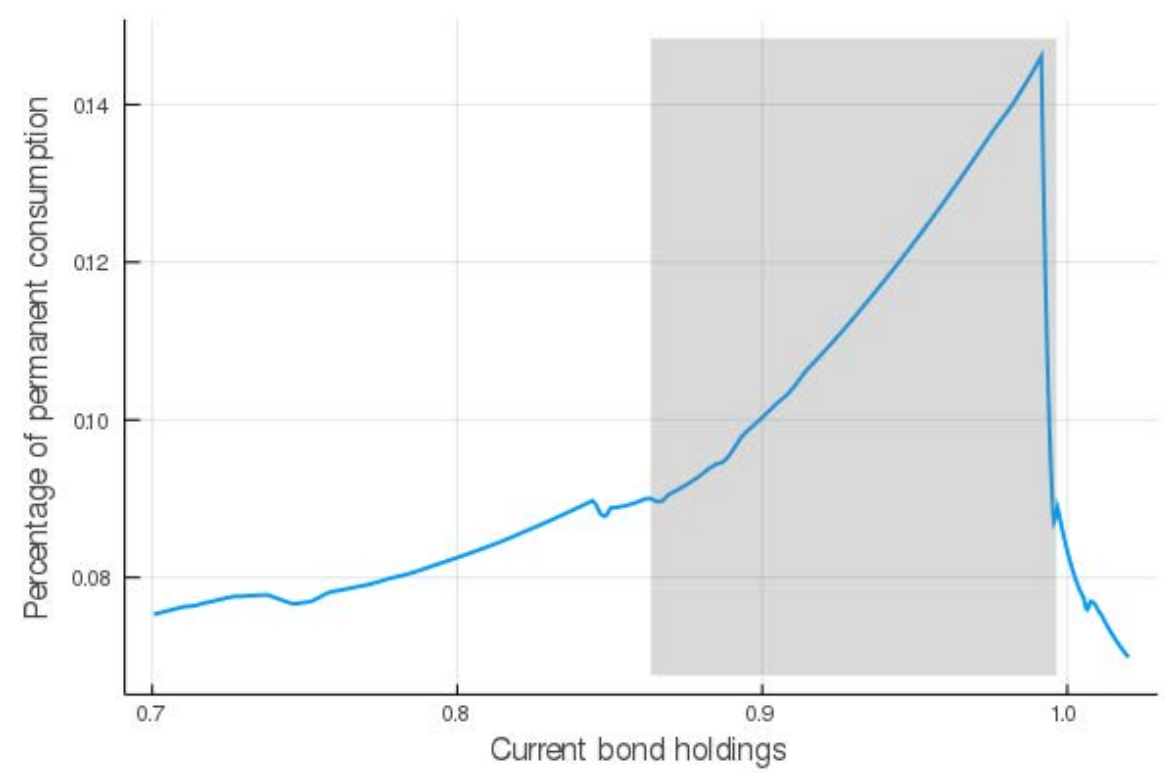

(b) Ergodic Distribution of Welfare Losses

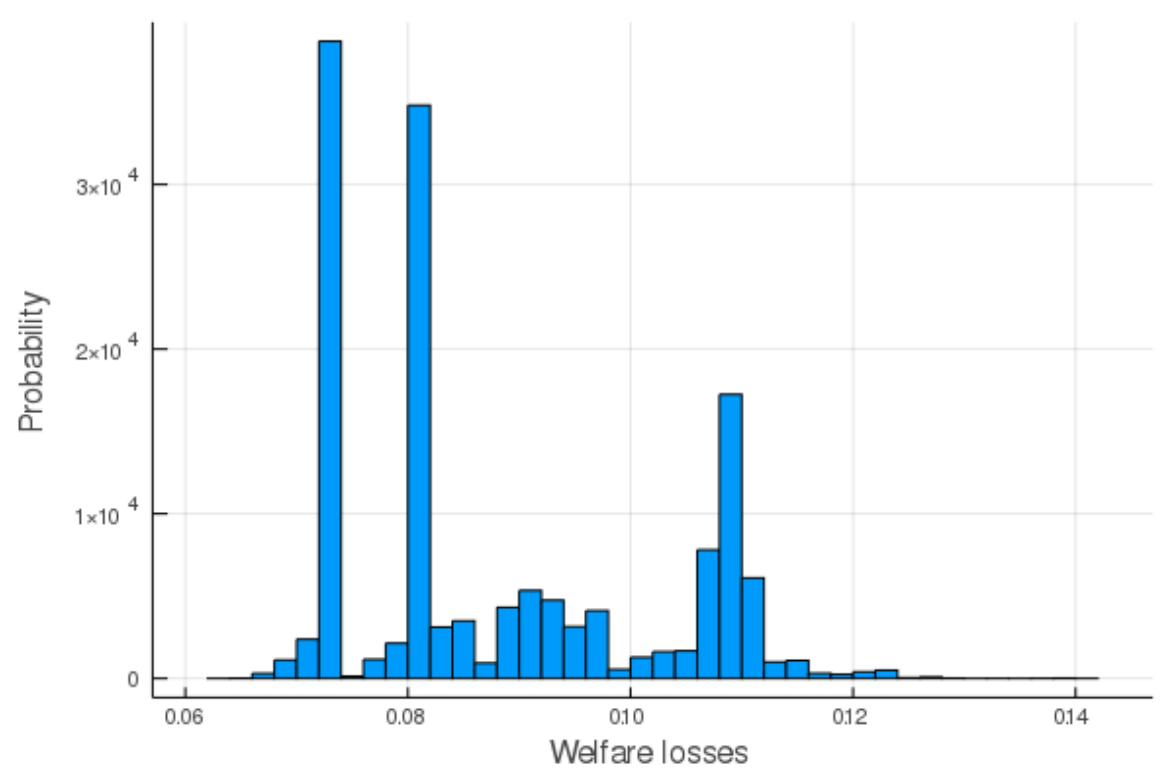

Notes: This figure plots the welfare losses from not implementing optimal capital control taxes in the currentincome-constraint economy. Panel (A) plots the welfare losses as a function of current bond holding for a given income level. Panel (B) plots the ergodic distribution of welfare losses in the constrained-efficient equilibrium. 
Figure B.6: Welfare Losses - Future Income

(a) Welfare Losses Conditional on Income

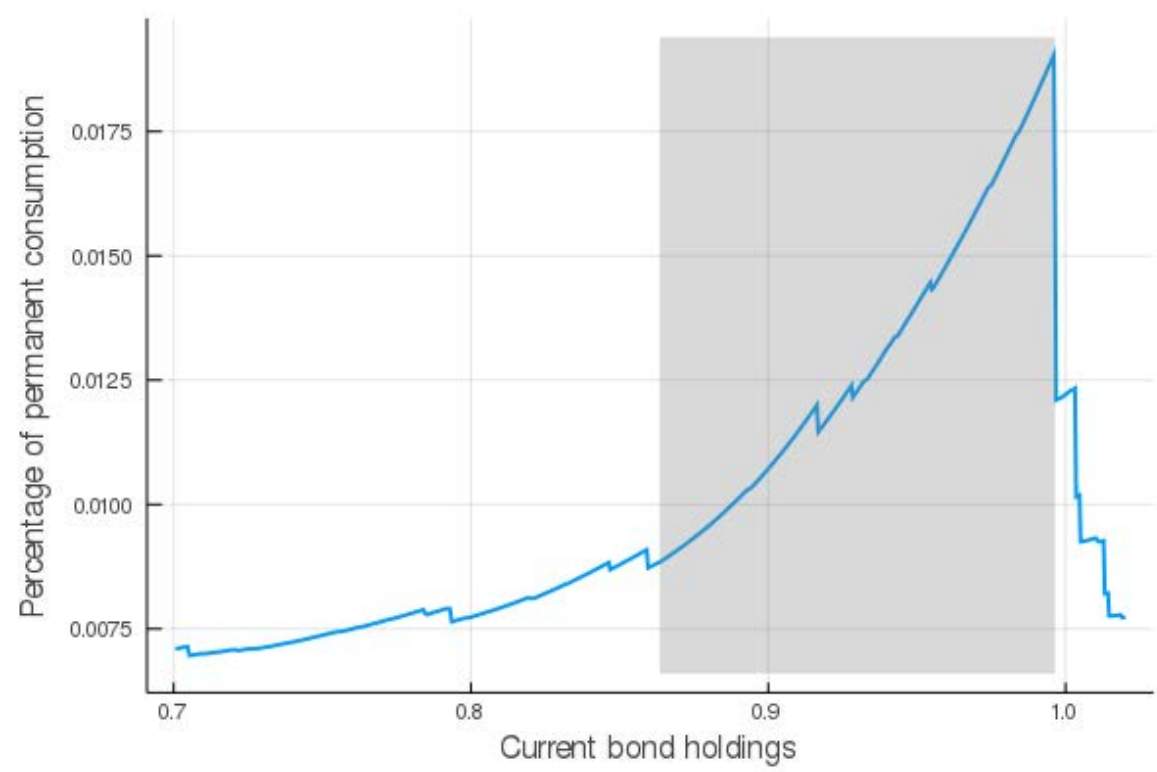

(b) Ergodic Distribution of Welfare Losses

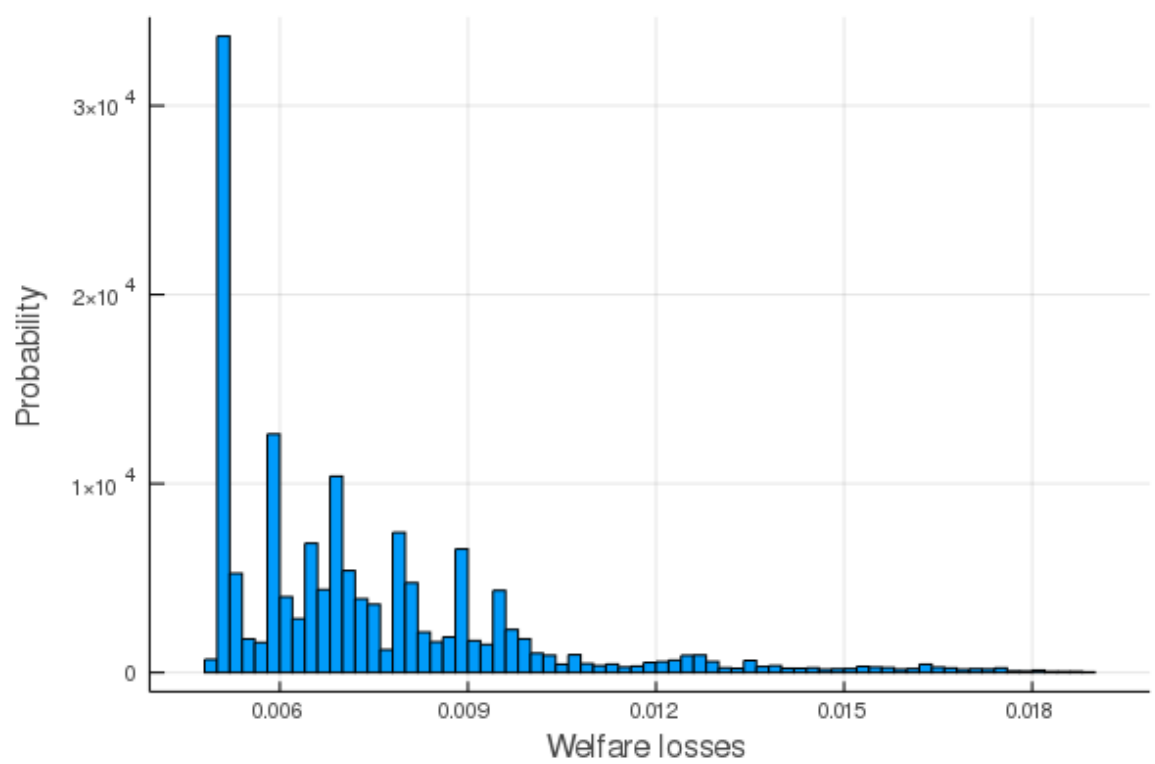

Notes: This figure plots the welfare losses from capital control taxes in the future-income-constraint economy. Panel (A) plots the welfare losses as a function of current bond holdings for a given income level. Panel (B) plots the ergodic distribution of welfare losses in the constrained-efficient equilibrium. 